\title{
BVVL/ FL: Features caused by SLC52A3 mutations; WDFY4 and TNFSF13B may be
}

\section{novel causative genes}

\author{
Marzieh Khani ${ }^{\mathrm{a}}$, Hosein Shamshiri ${ }^{\mathrm{b} \#}$, Hanieh Taheri ${ }^{\mathrm{a} \#}$, John Hardy ${ }^{\mathrm{c}}$, Jose Tomas Bras ${ }^{\mathrm{c}}$, Susana \\ Carmona $^{\mathrm{c}}$, Hamidreza Moazzeni ${ }^{\mathrm{a}}$, Afagh Alavi ${ }^{\mathrm{d}}$, Ali Heshmati ${ }^{\mathrm{a}}$, Peyman Taghizadeh ${ }^{\mathrm{a}}$, Yalda Nilipour ${ }^{\mathrm{e}}$, \\ Tooba Ghazanfarif ${ }^{\mathrm{f}}$, Majid Shahabi ${ }^{\mathrm{g}}$, Ali Asghar Okhovat ${ }^{\mathrm{b}}$, Mohammad Rohani ${ }^{\mathrm{h}}$, Giorgio Valle ${ }^{\mathrm{i}}$, Reza \\ Boostani $i^{j}$, Siamak Abdi ${ }^{\mathrm{b}}$, Shaghayegh Eshghi ${ }^{\mathrm{j}}$, Shahriar Nafissi ${ }^{{ }^{*}}$, Elahe Elahi ${ }^{*}$
}

${ }^{a}$ School of Biology, College of Science, University of Tehran, Tehran, Iran, ${ }^{b}$ Department of Neurology, Shariati Hospital, Tehran University of Medical Sciences, Tehran, Iran, ${ }^{c}$ Department of Molecular Neuroscience, Institute of Neurology, University College London, London, UK, ${ }^{\mathrm{d}}$ Genetics Research Center, University of Social Welfare and Rehabilitation Sciences, Tehran, Iran, ${ }^{\text {PPediatric }}$ Pathology Research Center, Research Institute for Children Health, Mofid and Shohaday-e Tajrish Hospital, Shahid Beheshti University of Medical Sciences, Tehran, Iran, ${ }^{\text {fSimorg Pathobiology }}$ Laboratory, Tehran, Iran, ${ }^{g}$ Blood Transfusion Research Center, High Institute for Research and Education in Transfusion Medicine, Tehran, Iran, ${ }^{\mathrm{h}}$ Department of Neurology, Hazrat Rasool Hospital, Iran University of Medical Sciences, Tehran, Iran, ${ }^{\mathrm{i}}$ Department of Biology and CRIBI Biotechnology Centre, University of Padova, Padova, Italy, ${ }^{\mathrm{j} D e p a r t m e n t ~ o f ~ N e u r o l o g y, ~ F a c u l t y ~ o f ~ M e d i c i n e, ~ M a s h h a d ~}$ University of Medical Sciences, Mashhad, Iran

\# These two authors contributed equally to this work.

* Corresponding author

Elahe Elahi

Professor, University College of Science, University of Tehran.

Full postal address: College of Science, University of Tehran, Enghelab Ave., Tehran 1417614411, Iran.

Phone: 0098-9122181251; Fax: 0098-2166405141.

E-Mail: elaheelahi@ut.ac.ir; elahe.elahi@gmail.com

Shahriar Nafissi

Professor, Dept. of Neurology, Tehran University of Medical Sciences, Tehran, Iran

Phone: 0098-9121060727; Fax: 0098-22884420

E-Mail: nafisi@sina.tums.ac.ir, s_nafissi@yahoo.com

Running head: BVVL/FL caused by SLC52A3, WDFY4, and TNFSF13B

No. Figures: 2

No. Tables: 3

No. Supplementary files: 9 
Brown-Vialetto-Van Laere(BVVL) and Fazio-Londe(FL) are disorders with ALS-like features, usually with recessive inheritance. We aimed to identify causative mutations in ten probands. Neurological examinations, genetic analysis, audiometry, MRI, biochemical and immunological testings, and/or muscle histopathology were performed. Mutations in known causative gene SLC52A3 were found in seven probands. More importantly, only one mutated allele was observed in several patients, and variable expressivity and incomplete penetrance were clearly noted. Environmental insults may contribute to variable presentations. Putative causative mutations in other genes were identified in three probands. Two of the genes, WDFY4 and TNFSF13B, have immune related functions. Inflammatory responses were implicated in the patient with the WDFY4 mutation. Malfunction of the immune system and mitochondrial anomalies were shown in the patient with the TNFSF13B mutation. Prevalence of heterozygous SLC52A3 BVVL causative mutations and notable variability in expressivity of homozygous and heterozygous genotypes are being reported for the first time. Identification of WDFY4 and TNFSF13B as candidate causative genes supports conjectures on involvement of the immune system in BVVL and ALS.

Key words: Brown-Vialetto-Van Laere (BVVL) syndrome, Fazio-Londe (FL) syndrome, 


\section{Introduction}

Brown-Vialetto-Van Laere syndrome (BVVL; MIM 211530) is a rare neurological disorder; approximately 150 cases have been reported(Manole et al., 2017; Sathasivam, 2008). BVVL is characterized by pontobulbar palsy, bilateral sensorineural hearing loss, and involvement of lower motor cranial nerves VII-XII. Upper motor neuron defects may appear with disease progression. Other possible manifestations include limb weakness and atrophy, speech defects, ocular anomalies, sensory symptoms/signs, and respiratory insufficiencies. Age at onset ranges from infancy to the third decade. BVVL is progressive, but progression rate is variable. Survival time ranges from a few years to several decades. Respiratory compromise is the most common cause of demise. The clinical features of BVVL overlap with those of several other motor neuron diseases, most notably juvenile amyotrophic lateral sclerosis (ALS) and Fazio-Londe (FL) syndrome. Absence of hearing loss distinguishes the latter from BVVL(McShane et al., 1992). Absence of hearing loss, less prominent bulbar presentations, later onset, asymmetric early presentations, and usually more rapid progression are ALS features that often allow differential diagnosis with BVVL(Yedavalli et al., 2018).

SLC52A3 that encodes solute carrier 52, riboflavin transporter, member 3, also known as RFVT3, was identified as a BVVL causative gene in 2010(Green et al., 2010). Inheritance was reported to be recessive. There has been a single report of involvement of SLC52A1, another member of the riboflavin transporter family(Ho et al., 2011). In 2012, mutations in SLC52A2 that encodes RFVT2, the only remaining riboflavin transporter in humans, were identified as cause of BVVL in a few patients with childhood onset motor neuron disease(Haack et al., 2012; Johnson et al., 2012). Contrary to SLC52A1, SLC52A2 mutations have been repeatedly found in BVVL patients(Ciccolella et al., 2013; Petrovski et al., 2015). Identification of BVVL causative mutations in riboflavin transporters and repeated documentation of benefits of riboflavin supplementation confirm that riboflavin deficiency 
contributes to BVVL etiology(Jaeger and Bosch, 2016). This notwithstanding, BVVL cases exist in whom mutations in the riboflavin transport genes were not identified(Johnson et al., 2012; Manole et al., 2017). Therefore, BVVL may have further genetic heterogeneity.

Here, we present clinical data and results of genetic analysis on ten Iranian BVVL- or FLdiagnosed probands. We discuss the implications of the findings.

\section{Methods}

This research was performed in accordance with the Declaration of Helsinki and with the approval of the ethics board of the University of Tehran.

\subsection{Subjects}

BVVL or FL diagnosed patients were referred for genetic analysis by the neurologists who are among the authors. Family members were recruited when possible. BVVL diagnosis was based on presence of motor neuronopathy with prominent cranial nerve involvement accompanied with hearing impairment. FL diagnosis was based on presence of motor neuronopathy with cranial nerve involvement without hearing impairment. Riboflavin was always prescribed at dosage of $10 \mathrm{mg} / \mathrm{kg}$ body weight/day. Audiometry assessment, electrodiagnostic (EDX) testing, brain magnetic resonance imaging (MRI), biochemical (including acylcarnitine profile measurements), immunological, fluorescent antinuclear antibody (FANA) testings, and histopathology were performed as described in Supplementary materials Text 1 .

\subsection{Genetic analysis}

Genetic analysis was performed as described in Supplementary materials Text 1. Briefly, the exons and flanking intronic sequences of SLC52A3 and SLC52A2 were initially sequenced in 
the probands as previously described(Dezfouli et al., 2012). Candidate disease causing variations were screened for segregation with disease status in the respective families and control individuals. Evolutionary conservation of amino acids affected by the mutations was checked. Whole exome sequencing was performed for probands without SLC52A3 and SLC52A2 mutations and also for several unaffected family members. Candidate disease causing variations that remained after filtering of the sequence data were screened for segregation with disease status in respective families and in control individuals.

\section{Results}

\subsection{Subjects}

One FL and nine BVVL diagnosed patients were referred (Fig. 1, Tables 1,2,S1,S2). The parents of eight probands were consanguineous. Interestingly, involvement of cranial nerve V that is usually not emphasized in BVVL, was observed in nine of the ten probands. Its involvement manifested with mastication problems and masseter muscle weakness, sometimes accompanied with atrophy. Involvement of the masseter muscle (that is responsible for mastication), which is not routinely tested in EMG studies, was also evidenced in EMG results of three (BVVL-102-II6, BVVL-103-II1, and BVVL-113-IV1) of four probands tested for this muscle, and also in four additional BVVL diagnosed relatives of BVVL-113-IV1. Presence of sensorineural hearing loss in the nine BVVL probands and some family members, and its absence in the FL proband were confirmed by audiometric testing. MRI images of individuals with hearing loss did not show structural defects. Brain MRI for the three probands without SLC52A3 mutations was done to possibly gain insight on disease etiology. 


\section{Families with $S L C 52 A 3$ mutations}

Probands BVVL-102-II6, BVVL-104-II1, BVVL-106-II3, BVVL-108-II1, BVVL-109-II1, BVVl-110-II2, and BVVL-113-IV1 had SLC52A3 mutations. Their pedigrees are shown in Figure 1A, and their clinical features are presented in Table 1. The data on the probands and their families are briefly elaborated upon here, and further described in Supplementary materials Text 2. An item of note was that genetic findings (see below) and family reports prompted clinical examination of family members of several probands. Results of clinical examinations, EDX evidence of motor neuronopathy, and presence of sensorineural hearing defects suggested that, in addition to proband BVVL-102-II6, her mother (-I2) and two siblings (-II3 and -II5) are also affected with BVVL (Table S1). Neurological examination of family members -I1, -II1, -II2, and -II4 was not possible. However, audiometric testing revealed that the father (-I1) and siblings -II1 and -II4 had sensorineural hearing loss, and that -II2 had normal hearing. Neurological examinations including EDX were normal for siblings -II2 and -II3 of proband BVVL-109-II1, but -II3 had severe sensorineural hearing defects; hearing of -II2 was normal. Family members reported that BVVL-109-II4, who was not examined, also had hearing problems. In family BVVL-110, only -I2 and -II6 consented to clinical examination; both were found to be normal. Hearing difficulties were reported for BVVL-110-II1 who was not examined. BVVL-113 is a large two-branched pedigree.

Pedigree members told us that there are six individuals (BVVL-113-II1, -II10, -III1, BVVL113-III10, -III12, and -III13) distributed in the two branches with hearing problems or other presentations similar to the proband. Five (all except BVVL-113-III1) were recruited and results of clinical examinations, including EDX evidence of motor neuronopathy, supported BVVL diagnosis in four (all except BVVL-113-II1) (Table S2). BVVL-113-III1, based on 
presentations described, is also probably affected. The only BVVL associated feature observed in BVVL-113-II1 was hearing loss which was confirmed by auditory testing.

Another notable item of BVVL families with SLC52A3 mutations, was coincidence of onset of BVVL-associated presentations with upper respiratory tract infections (BVVL-104-II1), tonsillitis (BVVl-110-II2), or severe fever and respiratory tract infection (BVVL-113-IV1) in three of the seven probands. Onset of hearing problems in individual BVVL-113-II1 who has the BVVL-associated genotype of his pedigree also presented immediately after a severe upper respiratory infection.

\section{Families without SLC52A3 mutations}

Probands BVVL-103-II1, BVVL-111-II3, and FL-101-II3 did not have SLC52A3 mutations. Their pedigrees are shown in Figure 1B, and their clinical features are presented in Table 2. The data on the probands are briefly elaborated upon here, and further described in Supplementary materials Text 2. Brain CT scan or brain MRI images were normal. None of these patients responded positively to riboflavin supplementation. BVVL-111-II3 had hearing problems from when he was 16 . He reports that he had no other symptom until three years ago at the age of 34 when he noticed dysarthria, dysphonia and dyspnea after a course of severe and long-lasting respiratory infection. FL-101-II3 experienced an episode of febrile seizure at age of six months before onset of symptoms.

In BVVL-111-II3, mildly elevated serum neutrophil and decreased lymphocyte levels and borderline alpha 1 antitrypsin levels were consistent with presence of an inflammatory response (Table S3)(Stockley, 2015). This was further supported by presence of anti-nuclear antibody evidenced as the few nuclear dot pattern by immunofluorescent microscopy (Fig. 2Aleft)(Damoiseaux et al., 2019). Results of other autoimmune related measurements were negative. Plasma lupus anticoagulant levels were normal. 
In FL-101-II3, there were multiple indications consistent with possible immune anomalies

196

197

198

199

200

201

202

203

204

205

206

207

208

209

210

211

212

213

214

215

216

217

218

219

(Table S4). The cytotoxic T-cell level was slightly high as compared to normal range, and the helper to cytotoxic T cell ratio was inverted. The B cell level as assessed by CD19 measurement was at the lower end of the normal range. Polyclonal immunoglobulin $\mathrm{G}$ and $\mathrm{M}$ levels in the serum were elevated. This increase, and elevated serum neutrophil and alpha 1 antitrypsin levels and decreased lymphocyte levels were consistent with presence of an inflammatory response(Stockley, 2015). Measurements of various autoimmune factors, including anti-dsDNA antibodies and lupus anticoagulants, were within normal ranges. However, presence of anti-nuclear antibodies that evidenced with the fine speckled pattern in the nucleus by fluorescent microscopy, is suggestive of an autoimmune and/or inflammatory response (Fig. 2Aright)(Damoiseaux et al., 2019). Mildly elevated LDH and CK levels are consistent with muscle involvement, and elevated lactate and lactate to pyruvate ratio are consistent with mitochondrial dysfunction. Some parameters of the patient's acylcarnitine profile, including methylmalonycarnitine (C4DC), hydroxyisovalerylcarnitine $(\mathrm{C} 5 \mathrm{OH})$, decenolylcarnitine (C10:1), and tetradecadienolycarnitine (C14:1) were not within the normal range. Abnormal acylcarnitine profiles may reflect defects in mitochondrial fatty acid betaoxidation catabolism(Wanders et al., 2010). Results of muscle histology confirmed presence of neurogenic muscle atrophy and some mitochondrial dysfunction that was evidenced in the laboratory results and clinical examinations. The muscle biopsy from the left vastus lateralis revealed marked muscle atrophy with a fascicular atrophy pattern. The remaining fibers were round and multiple nuclear clumps were associated with hypertrophied fibers with occasional fiber splitting (Fig 2Bleft). Succinate dehydrogenase (SDH) staining showed abnormal peripheral mitochondrial proliferation in some fibers (Fig. 2Bmiddle). The SDH plus cytochrome oxidase $(\mathrm{COX})$ reactions revealed a notable number of fibers with reduced COX activity which is consistent with neurogenic atrophy with some mitochondrial dysfunction 
(Fig. 2Bright). Histology of a biopsy from the left sural nerve showed no evidence of vasculitis, neither granuloma nor amyloid deposition (Fig. 2C).

\subsection{Genetic analysis}

\section{Families with SLC52A3 mutations}

Sequencing of SLC52A3 in the ten BVVL probands identified mutations in seven (Table 3, Fig. S1A). Mutations in SLC52A2 were not observed. Homozygous, compound heterozygous, and single heterozygous $S L C 52 A 3$ mutation, respectively, were observed in four, one, and two probands. The mutations had an allele frequency of $<0.01$ in all data bases checked, and were not observed in Iranian control individuals. They were all missense mutations that affected evolutionarily well conserved amino acids in RFVT3 (Table S5). The effects of all but p.Arg212Cys were considered damaging by various prediction tools. p.Arg212Cys was earlier reported as cause of BVVL(Manole et al., 2017). Seven different SLC52A3 mutations were found, three of which have not previously been reported. P.Asn21Ser was observed in more than one proband. All the patients with SLC52A3 mutations responded favorably to riboflavin intake.

Segregation analyses in the smaller families BVVL-104, -106, and -108 with SLC52A3 mutations were straightforward and suggested that their mutations cause BVVL in a recessive fashion (Fig. 1A). Heterozygous carriers were reported to be without BVVL related presentations, and audiometric testing on two carriers (BVVL-104-I2 and BVVL-108-I2) showed normal hearing. Results of segregation analysis in the remaining families with SLC52A3 mutations were more complicated.

The proband of BVVL-102 carried mutations p.Asn21Ser and p.Ala312Val. The BVVLdiagnosed mother and sibling -II5 had the same genotype as the proband. However, BVVLdiagnosed -II3 carried only the mutated allele p.Asn21Ser. The father (-I1) had the same 
genotype as this daughter, and siblings -II1, -II2, and -II4 were each heterozygous carriers of the alternate p.Ala312Val allele. Although family members reported absence of BVVL related clinical features in these four heterozygous individuals, audiometric testing as reported above revealed hearing defects in all except -II2.

Only one heterozygous mutation, p.Tyr329Cys, was found in proband BVVL-109-II1. Her parents and four siblings were available for segregation analysis. Unexpectedly, it was observed that all except the father had the same $S L C 52 A 3$ genotype as the proband. The father was homozygous for the wild type allele. The siblings had inherited the mutated allele from their mother, who had recently died due to causes unrelated to BVVL. Family members reported that she did not have hearing problems. As described above, the only BVVL-related symptom among the siblings was hearing loss in BVVL-109-II3 and -II4.

Proband BVVL-110-II2 was homozygous for p.Asn21Ser, one of the two mutations in BVVL-102-II6. Both parents and two siblings were carriers of the mutation, two siblings were homozygous for the mutated allele, and another was homozygous for the wild type allele. Neurological examination of the heterozygous mother and one heterozygous sibling showed that both were normal. Hearing problems were reported for only one of the siblings (BVVL-110-II1) homozygous for the mutated allele.

As with BVVL-109-II1, only one mutated allele was found in BVVL-113-IV1. His mutation was p.Gly13Arg. Each of four BVVL-diagnosed relatives, and also BVVL-113-III1 who presents with BVVL features, had the same heterozygous SLC52A3 genotype. BVVL-113-II1 who had hearing difficulties but no other BVVL-related symptom, also carried the mutated allele. Brain MRI of BVVL-113-II1 was normal. BVVL-113 members not included in Table S2 did not undergo clinical examination. Screening of the SLC52A3 mutation in twelve of these (age range: $28-70$ yrs.) revealed that seven were homozygous for the wild type allele 
and five were heterozygous carriers. Audiometric testing on one of these carriers (-III3) confirmed normal hearing.

\section{Families without SLC52A3 mutations}

271

272

Disease inheritance in families BVVL-103, BVVL-111, and FL-101 was consistent with an autosomal recessive pattern. There was only one affected individual in each family. The specifications of the exome sequencing data of a representative sample that reflect high quality sequencing are presented in Table S6. Analysis of exome data of probands and unaffected family members identified eight variations in seven genes in BVVL-103, twelve variations in eleven genes in BVVL-111, and seven variations in four genes in FL-101 that were present in the homozygous or compound heterozygous state only in the DNA of the respective proband (Table S7). Screening each of the variations in additional unaffected family members reduced the number of candidate causative variations to three in BVVL-103, and to one in the other two families.

The candidate variations of BVVL-103 were in SYCP1, VCAN, and BAIAP2 (Fig. S1B). These genes encode, respectively, synaptonemal complex protein 1, versican, and BAR/IMD domain containing adaptor protein 2 (alias IRSp53). Although c.3637A>G (p.Thr 1213Ala) in $V C A N$ is not reported in the databases, it is predicted to be non-damaging by various prediction tools and is assigned a very low CADD (Combined Annotation Dependent Depletion; https://cadd.gs.washington.edu/) value of 0.74. C.1918G>A (p.Glu640Lys) in SYCP1 (rs756169485) and c.1516C>T (p.Arg539Trp) in BAIAP2 (rs 149637388) are reported at very low frequencies (maximum: 0.0002 and 0.0023 , respectively), and only in the heterozygous state. These two variations are, respectively, assigned CADD scores of 25.5 and 15.78. Evolutionary conservation of affected amino acids of the encoded proteins is shown in Table S5. The amino acid (p.Thr1213) of VCAN is conserved among mammals. 
Alignment of orthologous proteins encoded by BAIAP2 suggests the region inclusive of the affected amino acid is present only in primates. The amino acid (p.Glu640) of SYCP1 is best conserved, being observed in mammals to fish. The single candidate variation of BVVL-111 was c.8851T>A (p.Ser2951Thr) in WDFY4 (Fig. S1B). The gene encodes WDFY Family Member 4 (WD repeat- and FYVE domain-containing protein 4). This variation in WDFY4 $(\mathrm{c} .8851 \mathrm{~T}>\mathrm{A})$ is not reported in the databases. It is predicted by various prediction tools to deleteriously affect the encoded protein; it has a CADD score of 23.9. The affected amino acid (p.Ser2951) is conserved in mammals and birds (Table S5). And the single remaining candidate variation of FL-101was a six nucleotide deletion c.276_281del(p.A93_G94del) in TNFSF13B (Fig. S1B). The variation has not been previously reported. The Proven software that is capable of assessing effects of deletion mutations on protein function predicted that the p.93_94 mutation would be damaging. TNFSF13B encodes TNF superfamily, member 13b (tumor necrosis factor (ligand) superfamily, member 13b).

\section{Discussion}

It is notable that ten Iranian BVVL/FL patients were identified within a period of a few years. Iranian neurologists have become familiar with BVVL/FL presentations and there may be minimum under-diagnosis of adult cases(Dezfouli et al., 2012). Additionally, consanguineous marriages are common in Iran. SLC52A2 mutations were not identified probably because the probands were referred by adult neurologists. Both adult- and child-onset forms of the diseases, because of rarity and overlap of symptoms with other anomalies, may be underdiagnosed worldwide.

Three of seven $S L C 52 A 3$ mutations here identified were novel. But more important are observed inheritance issues. Firstly, only one mutated allele was found in two (-109-II1 and - 

identification of causative genes, autosomal dominant inheritance for BVVL had been considered(Hawkins et al., 1990). To the best of our knowledge, our group was the first to have reported presence of only one mutated SLC52A3 mutated allele in BVVL diagnosed individuals(Dezfouli et al., 2012). By now, finding only one mutated allele in BVVL/FL diagnosed patients has been reported several times(Allison et al., 2017; Carreau et al., 2020; Ciccolella et al., 2012; Dezfouli et al., 2012; Manole et al., 2017). It appears justified to conclude that a heterozygous SLC52A3 mutation may in some cases cause BVVL or FL. The conclusion applies to mutations that affect amino acids distributed in the length of the encoded protein, possibly with some predominance in the first 40 amino acids (see Supplementary materials Text 3).

Another issue brought to light relates to expressivity and penetrance, which can be noted especially when segregation analysis is performed. BVVL-102 had BVVL diagnosed individuals with one or two mutated SLC52A3 alleles (Table S1). Severity of presentations was comparable in two patients of similar age with one (-II3) or two (-II5) mutated alleles. Age at onset of symptoms in two patients with two mutated alleles (-II5 and -II6) differed by nearly ten years. The father (-I1) and BVVL diagnosed daughter (-II3) both carried one copy of the same mutated allele (p.Asn21Val), but the only BVVL relevant presentation of the father was some sensorineural hearing loss. Hearing status of three siblings who were heterozygous for the alternate mutated allele of the family (-II1, -II2 and -II4; p.Ala312Val) was not the same.

The p.Asn21Val mutation of family -102 was also found in BVVL-110. Among three members of family BVVL-110 who were homozygous for the mutation, one (-II2) was diagnosed with BVVL, one (-II1) only had hearing problems, and the third (-II3) was reported to be asymptomatic. Unlike BVVL-affected BVVL-102-II3, two examined 
heterozygous carriers of p.Asn21Val in BVVL-110 (-I2 and -II6) were asymptomatic. These

342 findings evidence variable intrafamilial and interfamilial expressivity, and incomplete

343 penetrance. Apparently, both features may apply to genotypes that are heterozygous or

344 homozygous for mutated alleles.

Among three critically examined heterozygous carriers of p.Tyr329Cys in BVVL-109, -II1 was diagnosed with BVVL, -II3 only presented hearing loss, and -II2 was asymptomatic. Among six critically examined heterozygous carriers of p.Gly13Arg in BVVL-113, five were diagnosed with BVVL, and one only presented hearing loss. Five other heterozygous carriers of the mutation in the extended family were reported by themselves and family members to be asymptomatic. Audiometric testing was done on one of these (-III3) and results were normal. The unlikely possibility that the father (-I1) of BVVL-109 has a large deletion or carries an undetected mutation that was inherited only by offsprings -II1 and -II3 cannot be ruled out. Presence of an undetected mutation in patients of BVVL-113 seems even less likely, as the same mutation was also previously reported in the heterozygous state in patients of another study(Manole et al., 2017).

The totality of observations in BVVL families $-102,-110,-109$, and -113 argues in favor of variable expressivity and incomplete penetrance for $S L C 52 A 3$ mutated genotypes. A practical implication is that family members of BVVL patients with one or two SLC52A3 mutated alleles should be genotyped and/or regularly examined for presentation of symptoms. Environmental factors can be considered as contributing causes of the described differences. It is noted that disease onset coincided with fever, infection, or tonsillitis in some BVVL diagnosed individuals of families $-104,-110$ and -113 that had SLC52A3 mutations, and of families -101 and -111 without SLC52A3 mutations. Coincidence of BVVL onset with similar insults has also been reported elsewhere. Exposure to such insults may influence presentation and/or severity of disease (see below). 
SYCP1, VCAN, and BAIAP2 were retained candidate BVVL-causative genes in BVVL-103-

II1. The SYCPl-encoded protein is a component of the synaptonemal complex(Zickler and Kleckner, 2015). Available data do not suggest an obvious role for SYCP1 in neuromuscular pathology. VCAN and BAIAP2 may be better candidate BVVL culprit genes. (Additional references about VCAN and BAIAP2 are given in Supplementary materials, Text 4.) Versican encoded by $V C A N$ is a chondroitin sulfate proteoglycan with roles in myoblast proliferation and myotube formation(Stupka et al., 2013). It has been associated with skeletal muscle dystrophy pathology. Versilac, which is a naturally occurring proteolytic product of versican, can be pro-apoptotic or pro-inflammatory in some biological contexts. BAIAP2 (IRSp53) is considered an important regulator of membrane and actin dynamics at actin-rich subcellular structures such as filopodia and lamellipodia, is believed to affect neurite initiation and neuronal branching, and has been proposed to also affect mitochondrial morphology(Chen et al., 2015; Ferrari et al., 2016). The protein is expressed most strongly in the brain. BAIAP2 is concentrated at dendritic spines, in close association with the post synaptic density. Despite potential biological relevance of both $V C A N$ and $B A I A P 2$, bioinformatics tools predicted the VCAN variation in BVVL-103-II1 to be very benign. Therefore, based on the sum of bioinformatics predictions and known functions, the BAIAP2 mutation by affecting dendritic growth and/or mitochondrial functions may be the cause of BVVL in BVVL-103-II1.

WDFY4 and TNFSF13B were, respectively, the putative disease causing gene in BVVL-111II3 and FL-101-II3. A striking feature of these findings is that the major known functions of both genes are within the immune system. The longest WDFY4 transcript encodes a protein that has two BEACH domains, six WD40 repeats, and a truncated FYVE zinc finger domain (https://www.uniprot.org/uniprot/Q6ZS81). BEACH domains are implicated in membrane trafficking (https://www.ncbi.nlm.nih.gov/Structure/cdd/cddsrv.cgi?uid=cl10511). Disruption of this domain in human lysosomal trafficking regulator leads to Chediak-Higashi syndrome 
which presents with severe immunodeficiency and neurologic problems. WD40 repeats have multiple functions including signal transduction, pre-mRNA processing, and cytoskeleton assembly (https://www.ncbi.nlm.nih.gov/Structure/cdd/cddsrv.cgi?uid=207648). The mutation (p.Ser2951Thr) found in patient BVVL-111-II3 is positioned within the second WD domain (p.2923-p.2972) of WDFY4. WDFY4 is a membrane protein and the mouse orthologous locates in the endoplasmic reticulum and in endosomes (https://www.uniprot.org/uniprot/Q6ZS81). Although the protein is highly conserved during evolution, very little is known about its functions.

The most frequent attribute for WDFY4 is association with systemic lupus erythematosus (SLE) susceptibility and other autoimmune diseases including rheumatic arthritis, juvenile rheumatic arthritis, and clinically amyopathic dermatomysitis(Yang et al., 2010). Gene expression profiles show highest expression of WDFY4 in tissues with immune functions (https://www.ncbi.nlm.nih.gov/gene/57705). WDFY4 may also have roles in autophagy. WDFY3 (Gene ID: 23001), the closest paralog of WDFY4, encodes ALFY which interacts with p62 to organize misfolded ubiquitinated protein into bodies that become degraded by autophagy(Clausen et al., 2010). Blue cheese, the WDFY4 ortholog in drosophila, similarly functions in autophagy and also contributes to the development of the nervous system (https://flybase.org/reports/FBgn0043362.html). Direct evidence for involvement of WDFY4 in autophagy and link between autophagy and SLE susceptibility were recently derived from mouse knock out and cell culture knock down studies.

Indications of an inflammatory response in BVVL-111-II3 are consistent with involvement of the immune system in his disease. These indications may now be mild because the notable BVVL-related clinical features of this patient manifested only three years ago. Furthermore, immune system effects of WDFY4 in BVVL pathology may be subtle and not fully reflected 
in the analyses performed. Features pertaining to autophagy were not assessed in the patient. Further research on WDFY4 function may reveal how it contributes to BVVL pathology. TNFSF13B, also known as BAFF (B cell activating factor from the TNF family), is a member of the TNF gene superfamily of genes which have critical roles in inflammation and immune responses(Dostert et al., 2019). (Additional references on TNFSF13B and BAFF are given in Supplementary materials, Text 4.) BAFF is a transmembrane protein, and proteolytic cleavage within a stalk segment located between its transmembrane and extracellular domains produces a soluble form of the protein. The mutation (p.93_94del) in FL-101-II3 is within the stalk segment. BAFF has high expression in immune system related organs (https://www.ncbi.nlm.nih.gov/gene/10673), and is a cytokine ligand for receptors primarily expressed by B cells. It has important roles in the proliferation, differentiation, activation, and survival of B cells, and in T cell co-stimulation and T helper cell associated inflammatory responses(Mackay and Browning, 2002). BAFF is implicated in autoimmunity(Chen et al., 2014; Zhang et al., 2008). It has excessive expression in various autoimmune diseases, and overexpression in transgenic mice causes an autoimmune phenotype. Association studies recently identified a TNFSF $13 B$ variant associated with multiple sclerosis and SLE.

The aggregate of clinical data presented in the Results section on FL-101-II3 who harbors a TNFSF $13 B$ mutation are consistent with association of immune system malfunctions to her disease status. Notable features were inverted CD4/CD8 ratio, polyclonal gammapathy, and elevated alpha-1 levels. A declining CD4/CD8 ratio is an indicator of immunosenescence and an inverted ratio (less than 1/1) is considered to be a sign of an impaired immune system(McBride and Striker, 2017). Anomalies of the mitochondria were evidenced by lactate and pyruvate levels and by histopathology. The patient's acylcarnitine profile and presence of ptosis may also be indicators of mitochondrial malfunction(Lee et al., 2018). The mitochondrial anomalies may be secondary to immune dysfunction in the patient. It is of 
course of note that the common BVVL/FL causative gene $S L C 52 A 3$ also ultimately affects mitochondrial activity.

442 Although functional studies on BVVL/ FL have largely been limited to riboflavin 443 metabolism, there is reason to consider roles for immune functions in these diseases. In a review on BVVL that was published when only 58 patients had been described and well before identification of a causative gene, seven cases were reported in whom intercurrent infections may have precipitated or worsened BVVL presentation(Sathasivam, 2008). This scenario has since been reported in other publications, and also observed in five of the 10 probands in the present study(Bandettini Di Poggio et al., 2014; Dakhil et al., 2010). Three of the latter had mutations in SLC52A3 and two had mutations in other genes. Improvement of clinical presentations after immune therapy in some reported cases is also consistent with possible contribution of immune dysfunction to BVVL etiology(Bandettini Di Poggio et al., 2014). Finally, there are several reports of patients originally thought to be affected with a neuroimmune disorder, but ultimately diagnosed with BVVL on the basis of genetic testing(Allison et al., 2017).

Functional studies on ALS, whose etiology may have commonalities with BVVL/FL, have been more numerous. A role for the immune system in the etiology of ALS was considered since decades ago, and this proposal is now being given more attention. In fact, the immune system may have roles in various neurodegenerative disorders thus reflecting the interactions between these two important sensory systems(Lall and Baloh, 2017). The incidence of autoimmune diseases was reported to be higher among ALS patients as compared to controls(Turner et al., 2013). Similar results were reported for patients affected with 462 frontotemporal dementia (FTD) which is related to ALS(Miller et al., 2016). Some epidemiological studies have suggested a nearly fivefold increased risk of ALS associated with prior diagnosis of myasthenia gravis which is an autoimmune disease(de Pasqua et al., 
2017; Turner et al., 2013). Additionally, presence of multiple autoimmune antibodies and infiltration of inflammatory mediators in the CNS are implicated in ALS pathology(Hu et al., 2017; Lai and Ichida, 2019). Most interestingly, it is now considered that the hexanucleotide repeat expansion in C9ORF72 which is the most common cause of ALS, may also influence immune homeostasis(Lai and Ichida, 2019). Mouse knockouts of the orthologous gene present with various immune related dysfunctions(O'Rourke et al., 2016). Intermediate length repeats that are non-ALS-causing have been observed in individuals affected with progressive multiple sclerosis which is a neurodegenerative autoimmune disease(Tiloca et al., 2018). Involvement of the immune system with ALS pathology may to some extent also apply to BVVL and FL which are related diseases. Identification of WDFY4 and TNFSF 13B as potential BVVL causing genes supports this conjecture. Nevertheless, definitive assessment of contribution of these genes to BVVL pathology awaits finding mutations in these genes in other unrelated patients and further functional studies.

\section{Acknowledgements}

We acknowledge the Iran National Science Foundation and Tehran University of Medical Sciences for funding the research and thank the patients and their family members for participating in the study.

\section{Conflicts of Interest}

The authors declare that they have no conflict of interest. 
Allison, T., Roncero, I., Forsyth, R., Coffman, K., Pichon, J.L., 2017. Brown-Vialetto-Van Laere Syndrome as a Mimic of Neuroimmune Disorders: 3 Cases From the Clinic and Review of the Bandettini Di Poggio, M., Monti Bragadin, M., Reni, L., Doria-Lamba, L., Cereda, C., Pardini, M., Roccatagliata, L., Rossi, A., Schenone, A., 2014. Brown-Vialetto-Van Laere syndrome: clinical and neuroradiological findings of a genetically proven patient. Amyotroph Lateral Scler Frontotemporal Degener 15(1-2), 141-144.

Carreau, C., Lenglet, T., Mosnier, I., Lahlou, G., Fargeot, G., Weiss, N., Demeret, S., Salachas, F., Veauville-Merllie, A., Acquaviva, C., Nadjar, Y., 2020. A juvenile ALS-like phenotype dramatically improved after high-dose riboflavin treatment. Ann Clin Transl Neurol 7(2), 250-253.

Chen, C.J., Shih, C.H., Chang, Y.J., Hong, S.J., Li, T.N., Wang, L.H., Chen, L., 2015. SH2B1 and IRSp53 proteins promote the formation of dendrites and dendritic branches. J Biol Chem 290(10), 60106021.

Chen, M., Lin, X., Liu, Y., Li, Q., Deng, Y., Liu, Z., Brand, D., Guo, Z., He, X., Ryffel, B., Zheng, S.G., 2014. The function of BAFF on T helper cells in autoimmunity. Cytokine Growth Factor Rev 25(3), 301-305. Ciccolella, M., Catteruccia, M., Benedetti, S., Moroni, I., Uziel, G., Pantaleoni, C., Chiapparini, L., Bizzi, A., D'Amico, A., Fattori, F., Salsano, M.L., Pastore, A., Tozzi, G., Piemonte, F., Bertini, E., 2012. BrownVialetto-van Laere and Fazio-Londe overlap syndromes: a clinical, biochemical and genetic study. Neuromuscul Disord 22(12), 1075-1082.

Ciccolella, M., Corti, S., Catteruccia, M., Petrini, S., Tozzi, G., Rizza, T., Carrozzo, R., Nizzardo, M., Bordoni, A., Ronchi, D., D'Amico, A., Rizzo, C., Comi, G.P., Bertini, E., 2013. Riboflavin transporter 3 involvement in infantile Brown-Vialetto-Van Laere disease: two novel mutations. J Med Genet 50(2), 104-107.

Clausen, T.H., Lamark, T., Isakson, P., Finley, K., Larsen, K.B., Brech, A., Overvatn, A., Stenmark, H., Bjorkoy, G., Simonsen, A., Johansen, T., 2010. p62/SOSTM1 and ALFY interact to facilitate the formation of 162 bodies/ALIS and their degradation by autophagy. Autophagy 6(3), 330-344. Dakhil, F.O., Bensreiti, S.M., Zew, M.H., 2010. Pontobulbar palsy and sensorineural deafness (BrownVialetto-van Laere syndrome): the first case from Libya. Amyotroph Lateral Scler 11(4), 397-398. Damoiseaux, J., Andrade, L.E.C., Carballo, O.G., Conrad, K., Francescantonio, P.L.C., Fritzler, M.J., Garcia de la Torre, I., Herold, M., Klotz, W., Cruvinel, W.M., Mimori, T., von Muhlen, C., Satoh, M., Chan, E.K., 2019. Clinical relevance of HEp-2 indirect immunofluorescent patterns: the International Consensus on ANA patterns (ICAP) perspective. Ann Rheum Dis 78(7), 879-889.

de Pasqua, S., Cavallieri, F., D'Angelo, R., Salvi, F., Fini, N., D'Alessandro, R., Rinaldi, R., Fasano, A., Mandrioli, J., 2017. Amyotrophic lateral sclerosis and myasthenia gravis: association or chance occurrence? Neurol Sci 38(3), 441-444.

Dezfouli, M.A., Yadegari, S., Nafissi, S., Elahi, E., 2012. Four novel C20orf54 mutations identified in Brown-Vialetto-Van Laere syndrome patients. J Hum Genet 57(9), 613-617.

Dostert, C., Grusdat, M., Letellier, E., Brenner, D., 2019. The TNF Family of Ligands and Receptors: Communication Modules in the Immune System and Beyond. Physiol Rev 99(1), 115-160. Ferrari, I., Crespi, A., Fornasari, D., Pietrini, G., 2016. Novel localisation and possible function of LIN7 and IRSp53 in mitochondria of HeLa cells. Eur J Cell Biol 95(8), 285-293.

Green, P., Wiseman, M., Crow, Y.J., Houlden, H., Riphagen, S., Lin, J.P., Raymond, F.L., Childs, A.M., Sheridan, E., Edwards, S., Josifova, D.J., 2010. Brown-Vialetto-Van Laere syndrome, a ponto-bulbar palsy with deafness, is caused by mutations in c20orf54. Am J Hum Genet 86(3), 485-489. Haack, T.B., Makowski, C., Yao, Y., Graf, E., Hempel, M., Wieland, T., Tauer, U., Ahting, U., Mayr, J.A., Freisinger, P., Yoshimatsu, H., Inui, K., Strom, T.M., Meitinger, T., Yonezawa, A., Prokisch, H., 2012. Impaired riboflavin transport due to missense mutations in SLC52A2 causes Brown-Vialetto-Van Laere syndrome. J Inherit Metab Dis 35(6), 943-948. 
Hawkins, S.A., Nevin, N.C., Harding, A.E., 1990. Pontobulbar palsy and neurosensory deafness (Brown-Vialetto-Van Laere syndrome) with possible autosomal dominant inheritance. J Med Genet 27(3), 176-179. Ho, G., Yonezawa, A., Masuda, S., Inui, K., Sim, K.G., Carpenter, K., Olsen, R.K., Mitchell, J.J., Rhead, W.J., Peters, G., Christodoulou, J., 2011. Maternal riboflavin deficiency, resulting in transient neonatal-onset glutaric aciduria Type 2 , is caused by a microdeletion in the riboflavin transporter gene GPR172B. Hum Mutat 32(1), E1976-1984.

Hu, Y., Cao, C., Qin, X.Y., Yu, Y., Yuan, J., Zhao, Y., Cheng, Y., 2017. Increased peripheral blood inflammatory cytokine levels in amyotrophic lateral sclerosis: a meta-analysis study. Sci Rep 7(1), 9094.

Jaeger, B., Bosch, A.M., 2016. Clinical presentation and outcome of riboflavin transporter deficiency: mini review after five years of experience. J Inherit Metab Dis 39(4), 559-564.

Johnson, J.O., Gibbs, J.R., Megarbane, A., Urtizberea, J.A., Hernandez, D.G., Foley, A.R., Arepalli, S., Pandraud, A., Simon-Sanchez, J., Clayton, P., Reilly, M.M., Muntoni, F., Abramzon, Y., Houlden, H., Singleton, A.B., 2012. Exome sequencing reveals riboflavin transporter mutations as a cause of motor neuron disease. Brain 135(Pt 9), 2875-2882.

Lai, J.D., Ichida, J.K., 2019. C9ORF72 protein function and immune dysregulation in amyotrophic lateral sclerosis. Neurosci Lett 713, 134523.

Lall, D., Baloh, R.H., 2017. Microglia and C9orf72 in neuroinflammation and ALS and frontotemporal dementia. J Clin Invest 127(9), 3250-3258.

Lee, S.J., Na, J.H., Han, J., Lee, Y.M., 2018. Ophthalmoplegia in Mitochondrial Disease. Yonsei Med J 59(10), 1190-1196.

Mackay, F., Browning, J.L., 2002. BAFF: a fundamental survival factor for B cells. Nat Rev Immunol 2(7), 465-475.

Manole, A., Jaunmuktane, Z., Hargreaves, I., Ludtmann, M.H.R., Salpietro, V., Bello, O.D., Pope, S., Pandraud, A., Horga, A., Scalco, R.S., Li, A., Ashokkumar, B., Lourenco, C.M., Heales, S., Horvath, R., Chinnery, P.F., Toro, C., Singleton, A.B., Jacques, T.S., Abramov, A.Y., Muntoni, F., Hanna, M.G., Reilly, M.M., Revesz, T., Kullmann, D.M., Jepson, J.E.C., Houlden, H., 2017. Clinical, pathological and functional characterization of riboflavin-responsive neuropathy. Brain 140(11), 2820-2837. McBride, J.A., Striker, R., 2017. Imbalance in the game of T cells: What can the CD4/CD8 T-cell ratio tell us about HIV and health? PLoS Pathog 13(11), e1006624.

McShane, M.A., Boyd, S., Harding, B., Brett, E.M., Wilson, J., 1992. Progressive bulbar paralysis of childhood. A reappraisal of Fazio-Londe disease. Brain 115 ( Pt 6), 1889-1900.

Miller, Z.A., Sturm, V.E., Camsari, G.B., Karydas, A., Yokoyama, J.S., Grinberg, L.T., Boxer, A.L., Rosen, H.J., Rankin, K.P., Gorno-Tempini, M.L., Coppola, G., Geschwind, D.H., Rademakers, R., Seeley, W.W., Graff-Radford, N.R., Miller, B.L., 2016. Increased prevalence of autoimmune disease within C9 and FTD/MND cohorts: Completing the picture. Neurol Neuroimmunol Neuroinflamm 3(6), e301. O'Rourke, J.G., Bogdanik, L., Yanez, A., Lall, D., Wolf, A.J., Muhammad, A.K., Ho, R., Carmona, S., Vit, J.P., Zarrow, J., Kim, K.J., Bell, S., Harms, M.B., Miller, T.M., Dangler, C.A., Underhill, D.M., Goodridge, H.S., Lutz, C.M., Baloh, R.H., 2016. C9orf72 is required for proper macrophage and microglial function in mice. Science 351(6279), 1324-1329.

Petrovski, S., Shashi, V., Petrou, S., Schoch, K., McSweeney, K.M., Dhindsa, R.S., Krueger, B., Crimian, R., Case, L.E., Khalid, R., El-Dairi, M.A., Jiang, Y.H., Mikati, M.A., Goldstein, D.B., 2015. Exome sequencing results in successful riboflavin treatment of a rapidly progressive neurological condition. Cold Spring Harb Mol Case Stud 1(1), a000257.

Sathasivam, S., 2008. Brown-Vialetto-Van Laere syndrome. Orphanet J Rare Dis 3, 9. Stockley, R.A., 2015. The multiple facets of alpha-1-antitrypsin. Ann Transl Med 3(10), 130. Stupka, N., Kintakas, C., White, J.D., Fraser, F.W., Hanciu, M., Aramaki-Hattori, N., Martin, S., Coles, C., Collier, F., Ward, A.C., Apte, S.S., McCulloch, D.R., 2013. Versican processing by a disintegrin-like and metalloproteinase domain with thrombospondin-1 repeats proteinases- 5 and -15 facilitates myoblast fusion. J Biol Chem 288(3), 1907-1917. 
Tiloca, C., Sorosina, M., Esposito, F., Peroni, S., Colombrita, C., Ticozzi, N., Ratti, A., MartinelliBoneschi, F., Silani, V., 2018. No C9orf72 repeat expansion in patients with primary progressive multiple sclerosis. Mult Scler Relat Disord 25, 192-195.

Turner, M.R., Goldacre, R., Ramagopalan, S., Talbot, K., Goldacre, M.J., 2013. Autoimmune disease preceding amyotrophic lateral sclerosis: an epidemiologic study. Neurology 81(14), 1222-1225. Wanders, R.J., Ruiter, J.P., L, I.J., Waterham, H.R., Houten, S.M., 2010. The enzymology of mitochondrial fatty acid beta-oxidation and its application to follow-up analysis of positive neonatal screening results. J Inherit Metab Dis 33(5), 479-494.

Yang, W., Shen, N., Ye, D.Q., Liu, Q., Zhang, Y., Qian, X.X., Hirankarn, N., Ying, D., Pan, H.F., Mok, C.C., Chan, T.M., Wong, R.W., Lee, K.W., Mok, M.Y., Wong, S.N., Leung, A.M., Li, X.P., Avihingsanon, Y., Wong, C.M., Lee, T.L., Ho, M.H., Lee, P.P., Chang, Y.K., Li, P.H., Li, R.J., Zhang, L., Wong, W.H., Ng, I.O., Lau, C.S., Sham, P.C., Lau, Y.L., Asian Lupus Genetics, C., 2010. Genome-wide association study in Asian populations identifies variants in ETS1 and WDFY4 associated with systemic lupus erythematosus. PLoS Genet 6(2), e1000841. Yedavalli, V.S., Patil, A., Shah, P., 2018. Amyotrophic Lateral Sclerosis and its Mimics/Variants: A Comprehensive Review. J Clin Imaging Sci 8, 53.

Zhang, W., Wen, L., Huang, X., Liang, J., Gao, W., Zhang, S., Chen, L., 2008. hsBAFF enhances activity of NK cells by regulation of CD4(+) T lymphocyte function. Immunol Lett 120(1-2), 96-102.

Zickler, D., Kleckner, N., 2015. Recombination, Pairing, and Synapsis of Homologs during Meiosis. Cold Spring Harb Perspect Biol 7(6). 
Figure 1- Pedigrees of BVVL/FL affected probands. A. Pedigrees of seven probands with are identified with arrow. Proband of FL-101 was diagnosed with FL and probands of other families were diagnosed with BVVL. *, individuals who underwent complete neurological examination including EMG and NCS; black filled symbols, diagnosed with BVVL or FL; H, individual whose only BVVL-relevant presentation is sensorineural hearing defect; MM, homozygous mutant genotype; $\mathrm{MN}$, heterozygous genotype; $\mathrm{NN}$, normal genotype; in pedigree of family BVVL-102 that has compound heterozygous SLC52A3 mutations, genotypes of both mutations are shown; in BVVL-103, the genotypes of proband and parents are for mutations in each of three genes (SYCP1, VCAN, and BAIAP2), and the siblings of the proband were either heterozygous carriers of mutations in the genes or were homozygous for the wild type alleles (see text); the mutations in BVVL-111 and FL-101 are, respectively, in WDFY4 and TNFSF13B. of muscle and nerve tissue. A. Fluorescent microscope images. Left: Presence of antinuclear antibodies in the serum of proband BVVL-111-II3 evidences as few nuclear dots. Right: Presence of antinuclear antibodies in the serum of proband FL-101-II3 evidences as the fine speckled pattern. B. Histopathology images of FL-101-II3 muscle biopsy was from left vastus lateralis. Left: Hematoxylin and eosin staining reveals marked muscle atrophy with fascicular atrophy pattern. Multiple nuclear clumps are seen associated with few hypertrophied fibers. Middle: SDH (succinate dehydrogenase) staining shows abnormal peripheral mitochondrial proliferation. Right: Blue fibers (arrows) observed after COX-SDH 
643 histochemical staining indicate decrease in COX (cytochrome c oxidase) activity and 644 increased SDH activity, possibly due to mitochondrial hyper proliferation. C. Histopathology 645 image of nerve biopsy from left sural nerve. Hematoxylin and eosin staining does not show 646 abnormality.

647

648 Figure S1- Chromatograms of mutations observed in nine BVVL and one FL proband.

649 A. Chromatograms of mutations observed in SLC52A3 in seven BVVL probands. B. 650 Chromatograms pertaining to three candidate BVVL causing mutations in BVVL-103 651 proband, putative BVVL causing WDFY4 mutation in BVVL-111 proband, and putative FL 652 causing TNFSF $13 B$ mutation in FL-101 proband. 
Table S1- Clinical data on four BVVL diagnosed individuals of pedigree BVVL-102 with mutations in SLC52A3

\begin{tabular}{|c|c|c|c|c|}
\hline Individual ID & BVVL-102-12 & BVVL-102-II3 & BVVL-102-II5 & BVVL-102-116* \\
\hline \multirow[t]{2}{*}{ Genotype } & Comp. het.: c.62A>G (p.Asn21Ser)/ & Het.: c.62A>G (p.Asn21Ser) & Comp. het.: c.62A>G (p.Asn21Ser)/ & Comp. het.: c.62A>G (p.Asn21Ser)/ \\
\hline & c.935c>T (p.Ala312Val) & & c.935C>T (p.Ala312Val) & c.935c>T (p.Ala312Val) \\
\hline Sex & female & female & male & female \\
\hline Age at examination (=present age) & 55 yrs & 33 yrs & 31 yrs & 27 yrs \\
\hline Age at onset & 25 yrs & 32 yrs & 28 yrs & $19 \mathrm{yrs}$ \\
\hline Disease duration & 30 yrs & $1 \mathrm{yr}$ & $3 \mathrm{yrs}$ & $8 \mathrm{yrs}$ \\
\hline \multirow[t]{2}{*}{ Initial presentation } & weakness of lower extremities & hearing problem \& & hearing problem & dysphagia \\
\hline & & weakness of lower extremities & & \\
\hline \multirow[t]{3}{*}{ Bulbar palsy $(\mathrm{CN}-9,12)$} & + & - & - & + \\
\hline & dysarthria, dysphagia \& & & & dysphagia, dysarthria, \\
\hline & tongue fasciculation & & & tongue atrophy \\
\hline CN-5 palsy & - & - & - & mastication problems \\
\hline Facial weakness (CN-7) & + weakness & - & - & $\begin{array}{l}\text { weakness, atrophy, } \\
\text { fasciculation }\end{array}$ \\
\hline Hearing problem (CN-8) & + & + & + & + \\
\hline Ophthalmoplegia (CN3/4/6 palsy) & - & - & - & - \\
\hline Ptosis & - & - & - & - \\
\hline Optic nerve atrophy (CN-2 involvement) & - & - & - & - \\
\hline \multirow[t]{2}{*}{ Limb weakness } & + upper and lower extremities & + proximal weakness, more prominent & - & + \\
\hline & & in right lower extremity & & \\
\hline Limb muscle atrophy & + upper and lower extremities & - & - & +, distal atrophy \\
\hline Spasticity & - & - & - & - \\
\hline Increased DTR & + & - & + & + \\
\hline Decreased DTR & - & - & - & - \\
\hline Sensory symptoms/ signs & - & - & - & - \\
\hline Tremor & - & - & - & - \\
\hline Ataxia & - & - & - & - \\
\hline Vertigo & - & - & - & + \\
\hline Tinnitus & - & - & - & - \\
\hline Seizure & - & - & - & - \\
\hline Mental impairment & - & - & - & - \\
\hline Psychiatric disorder & - & - & - & + , depression \\
\hline Autonomic disfunction & - & - & - & - \\
\hline Upward plantar reflex & - & - & - & - \\
\hline Respiratory problem & - & - & - & - \\
\hline \multirow[t]{2}{*}{ Ambulatory state } & slower but assstive & no limitation & no limitation & no limitation \\
\hline & device or help not needed & & & \\
\hline Acylcarnitine profile & not done & not done & not done & not done \\
\hline \multirow[t]{3}{*}{ EMG } & motor neuronopathy & motor neuronopathy & motor neuronopathy & motor neuronopathy, more \\
\hline & at extremities and & at extremities and & at extremities and & prominent but not restricted \\
\hline & cranial and truncal levels & cranial and truncal levels & cranial and truncal levels & to cranial myotomes \\
\hline NCS & Normal sensory findings & Normal sensory findings & Normal sensory findings & Normal sensory findings \\
\hline
\end{tabular}

*, Proband of BVVL-102, also described in Table 1. Comp. het, compound heterozygous; Het, heterozygous; CN, cranial nerve; DTR, deep tendon reflexes; EMG, electromyography; NCS; nerve conduction studies 
Table S2- Clinical data on five BVVL diagnosed individuals of pedigree BVVL-113 with mutation in SLC52A3 (c.37G>A; p.Gly13Arg)*

\begin{tabular}{|c|c|c|c|c|c|}
\hline Individual ID & BVVL-113-II10 & BVVL-113-III10 & BVVL-113-III12 & BVVL-113-III13 & BVVL-113-IV1** \\
\hline Sex & male & male & male & female & male \\
\hline Age at examination (=present age) & $53 \mathrm{yrs}$ & $30 \mathrm{yrs}$ & 25 yrs & 23 yrs & $19 \mathrm{yrs}$ \\
\hline Age at onset & $20 \mathrm{yrs}$ & 15 yrs & 9 yrs & 13 yrs & 9 yrs \\
\hline Disease duration & 33 yrs & 15 yrs & 16 yrs & 10 yrs & $10 \mathrm{yrs}$ \\
\hline Initial presentation & hearing problem and dysequilibrium & hearing problem & hearing problem & dysphonia (partial laryngeal paralysis) & asymmetric facial weakness \\
\hline Bulbar palsy $(\mathrm{CN}-9,12)$ & $\begin{array}{l}+ \\
\text { mild dysphagia, dysarthria } \\
\text { and tongue atrophy }\end{array}$ & $\begin{array}{c}+ \\
\text { dysphonia }\end{array}$ & $\begin{array}{l}\stackrel{+}{\text { dysphagia, dysarthria }} \\
\text { and tongue atrophy }\end{array}$ & $\begin{array}{c}\stackrel{+}{+}{ }^{+} \text {dysphonia, dysarthria } \\
\text { and tongue atrophy }\end{array}$ & $\begin{array}{l}+ \\
\text { mild dysphagia, dysarthria, } \\
\text { tongue atrophy }\end{array}$ \\
\hline CN-5 palsy & - & - & 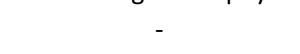 & - & mastication problems and atrophy \\
\hline Facial weakness (CN-7) & + weakness & - & + weakness & + weakness & weakness, atrophy \\
\hline Hearing problem (CN-8) & + & + & + & + & + \\
\hline Ophthalmoplegia (CN3/4/6 palsy) & 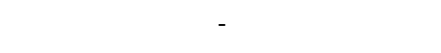 & + right CN6 paresia and nystagmus at right gaze & - & - & - \\
\hline Ptosis & - & & - & - & - \\
\hline \multirow{2}{*}{$\begin{array}{l}\text { Optic nerve atrophy (CN-2 involvement) } \\
\text { Limb weakness }\end{array}$} & . & - & - & & - \\
\hline & - & + distal lower extremities (foot drop) & - & $\begin{array}{l}+ \text { mild symmetric in upper } \\
\text { and lower extremities }\end{array}$ & - \\
\hline Limb muscle atrophy & - & + distal lower extremities & & - & - \\
\hline Spasticity & & - & - & & - \\
\hline Increased DTR & - & - & - & + & - \\
\hline Decreased DTR & - & + & - & - & - \\
\hline \multicolumn{2}{|l|}{ Sensory symptoms/ signs } & - & - & & - \\
\hline Tremor & + hand and head & - & + hand and head & thand & - \\
\hline Ataxia & + & - & + & + & - \\
\hline Vertigo & - & - & - & - & - \\
\hline Tinnitus & - & - & - & - & - \\
\hline Seizure & - & - & & - & - \\
\hline Mental impairment & - & - & - & - & - \\
\hline Psychiatric disorder & - & - & - & - & - \\
\hline Autonomic disfunction & . & - & - & - & - \\
\hline Upward plantar reflex & & - & - & + & - \\
\hline Respiratory problem & & . & . & & . \\
\hline Ambulatory state & no limitation & slow, uses braces but does not need help & & & \\
\hline Acylcarnitine profile & not done & not done & not done & not done & not done \\
\hline \multirow[t]{3}{*}{ EMG } & motor neuronopathy & motor neuronopathy & motor neuronopathy & motor neuronopathy & motor neuronopathy, more \\
\hline & restricted to cranial myotomes & at extremities and & at extremities and & at extremities and & prominent but not restricted \\
\hline & & cranial and truncal levels & cranial and truncal levels & cranial and truncal levels & to cranial myotomes \\
\hline NCS & Normal sensory findings & Normal sensory findings & Normal sensory findings & Normal sensory findings & Normal sensory findings \\
\hline
\end{tabular}

*, BVVL-113-II1 aged 40 yrs old, not diagnosed with BVVL, is not included in the Table. Hearing problems, with onset 15 years earlier, are his only BVVL relevant presentation. **Proband of BVVL-113, also described in Table 1.

CN, cranial nerve; DTR, deep tendon reflexes; EMG, electromyography; NCS; nerve conduction studies 
Table S3- Clinical laboratory measurements of BVVL-111 proband*

\begin{tabular}{|c|c|c|}
\hline Test item & $\begin{array}{l}\text { Measurement } \\
\text { in patient }\end{array}$ & $\begin{array}{c}\text { Normal } \\
\text { range }\end{array}$ \\
\hline RBC & $6.7 \times 10^{6} / \mu \mathrm{L}$ & $4.5-6.2 \times 10^{6} / \mu \mathrm{L}$ \\
\hline $\mathrm{Hb}$ & $17.1 \mathrm{mg} / \mathrm{dL}$ & $12-16 \mathrm{mg} / \mathrm{dL}$ \\
\hline Hct & $54.70 \%$ & $38.8-46.4 \%$ \\
\hline Neutrophil differential & $73.70 \%$ & $50-70 \%$ \\
\hline Lymphocytel differential & $15.70 \%$ & $25-45 \%$ \\
\hline Ferritin & $13 \mathrm{ng} / \mathrm{mL}$ & $30-300 \mathrm{ng} / \mathrm{mL}$ \\
\hline Blood PO2 & $42.4 \mathrm{mmHg}$ & $75-100 \mathrm{mmHg}$ \\
\hline $\mathrm{LDH}$ & $400 \mathrm{U} / \mathrm{L}$ & $180-400 \mathrm{U} / \mathrm{L}$ \\
\hline CPK & $79 \mathrm{U} / \mathrm{L}$ & $20-180 \mathrm{U} / \mathrm{L}$ \\
\hline CRP & $<2 \mathrm{mg} / \mathrm{L}$ & $<10 \mathrm{mg} / \mathrm{L}$ \\
\hline Alpha 1 antitrypsin & $0.29 \mathrm{~g} / \mathrm{dL}$ & $0.10-0.30 \mathrm{~g} / \mathrm{dL}$ \\
\hline Serum IgG & $1168 \mathrm{mg} / \mathrm{dL}$ & $700-1600 \mathrm{mg} / \mathrm{dL}$ \\
\hline Serum IgA & $340 \mathrm{mg} / \mathrm{dL}$ & $70-400 \mathrm{mg} / \mathrm{dL}$ \\
\hline Serum IgM & $98 \mathrm{mg} / \mathrm{dL}$ & $40-230 \mathrm{mg} / \mathrm{dL}$ \\
\hline CD4 & $46.40 \%$ & $20-65 \%$ \\
\hline CD8 & $25.30 \%$ & $10-40 \%$ \\
\hline CD4:CD8 ratio & 1.83 & $1-4$ \\
\hline CD19 & $8.90 \%$ & $4-25 \%$ \\
\hline CD20 & $9.00 \%$ & $4-25 \%$ \\
\hline $\mathrm{CH} 50$ & $100 \mathrm{U}$ & $70-150 \mathrm{U}$ \\
\hline Complement C3 & $105 \mathrm{mg} / \mathrm{dL}$ & $90-180 \mathrm{mg} / \mathrm{dL}$ \\
\hline Complement C4 & $27 \mathrm{mg} / \mathrm{dL}$ & $10-40 \mathrm{mg} / \mathrm{dL}$ \\
\hline Anti mitochondrial $\mathrm{Ab}$ & negative & negative $(=<1: 10)$ \\
\hline Rheumatoid factor & $4.0 \mathrm{IU} / \mathrm{mL}$ & $0-30 \mathrm{IU} / \mathrm{mL}$ \\
\hline Anti-dsDNA & $2.2 \mathrm{IU} / \mathrm{mL}$ & $<12 \mathrm{IU} / \mathrm{mL}$ \\
\hline Anti-nuclear antibody & 1:320 titer & $<1: 100$ negative \\
\hline
\end{tabular}

* Measurements of items considered most relevant to BVVL or known functions of WDFY4 are reported in the Table. Blood biochemistry including sugar, cholesterol, and triglyceride levels, thyroid hormones, and vitamin D measurements were within normal range. Plasma lactate and pyruvate, and their ratio were normal. Levels of amino acids associated with metabolic disorders, and acyl carnitine profile that included measurements of 28 compounds were normal. CD4 and CD8 are, respectively, markers for helper and cytotoxic T-cells, and CD19 and CD20 are B cell markers. Percent of cells with T-cell and B-cell markers were assessed by flow cytometry. $\mathrm{CH} 50$ is an index for total complemtary level. Anti-nuclear antibody was assessed by fluorescent microscopy.

fluorescent microscopy. 
Table S4- Clinical laboratory measurements of FL-101 proband*

\begin{tabular}{|c|c|c|}
\hline Test item & $\begin{array}{l}\text { Measurement } \\
\text { in patient }\end{array}$ & $\begin{array}{c}\text { Normal } \\
\text { range }\end{array}$ \\
\hline RBC & $5.3 \times 10^{6} / \mu \mathrm{L}$ & $4.0-5.2 \times 10^{6} / \mu \mathrm{L}$ \\
\hline $\mathrm{Hb}$ & $15.6 \mathrm{~g} / \mathrm{dL}$ & $12-16 \mathrm{~g} / \mathrm{dL}$ \\
\hline Hct & $47.30 \%$ & $36-46 \%$ \\
\hline Neutrophil differential & $77.00 \%$ & $50-70 \%$ \\
\hline Lymphocytel differential & $17.00 \%$ & $25-45 \%$ \\
\hline $\mathrm{LDH}$ & $440 \mathrm{U} / \mathrm{L}$ & $180-400 \mathrm{U} / \mathrm{L}$ \\
\hline CPK & $230 \mathrm{U} / \mathrm{L}$ & $20-160 \mathrm{U} / \mathrm{L}$ \\
\hline Plasma lactate & $26 \mathrm{mg} / \mathrm{dL}$ & $4.5-20 \mathrm{mg} / \mathrm{dL}$ \\
\hline Plasma pyruvate & $0.9 \mathrm{mg} / \mathrm{dL}$ & $0.3-0.9 \mathrm{mg} / \mathrm{dL}$ \\
\hline Lactate: Pyruvate ratio & 28.9 & $<20$ \\
\hline CRP & $2 \mathrm{mg} / \mathrm{L}$ & $<10 \mathrm{mg} / \mathrm{L}$ \\
\hline Alpha 1 antitrypsin & $0.32 \mathrm{~g} / \mathrm{dL}$ & $0.10-0.30 \mathrm{~g} / \mathrm{dL}$ \\
\hline Serum IgG & $1730 \mathrm{mg} / \mathrm{dL}$ & $700-1600 \mathrm{mg} / \mathrm{dL}$ \\
\hline Serum IgA & $145 \mathrm{mg} / \mathrm{dL}$ & $70-400 \mathrm{mg} / \mathrm{dL}$ \\
\hline Serum IgM & $240 \mathrm{mg} / \mathrm{dL}$ & $40-230 \mathrm{mg} / \mathrm{dL}$ \\
\hline CD4 & $37.70 \%$ & $20-65 \%$ \\
\hline CD8 & $48.30 \%$ & $10-40 \%$ \\
\hline CD4:CD8 ratio & 0.78 & $1-4$ \\
\hline CD19 & $6.90 \%$ & $4-25 \%$ \\
\hline $\mathrm{CH} 50$ & $100 \mathrm{U}$ & $70-150 \mathrm{U}$ \\
\hline Complement C3 & $127 \mathrm{mg} / \mathrm{dL}$ & $90-180 \mathrm{mg} / \mathrm{dL}$ \\
\hline Complement C4 & $22 \mathrm{mg} / \mathrm{dL}$ & $10-40 \mathrm{mg} / \mathrm{dL}$ \\
\hline Anti mitochondrial $\mathrm{Ab}$ & negative & negative $(=<1: 10)$ \\
\hline Rheumatoid factor & $3.6 \mathrm{IU} / \mathrm{mL}$ & $0-30 \mathrm{IU} / \mathrm{mL}$ \\
\hline Anti dsDNA & $2.0 \mathrm{IU} / \mathrm{mL}$ & $<12 \mathrm{IU} / \mathrm{mL}$ \\
\hline Anti nuclear antibody & 1:160 titer & $<1: 100$ negative \\
\hline Methylmalonycarnitine (C4DC) & $0.49 \mu \mathrm{M}$ & $<0.22 \mu \mathrm{M}$ \\
\hline Hydroxyisovalerylcarnitine $(\mathrm{C} 5 \mathrm{OH})$ & $0.52 \mu \mathrm{M}$ & $<0.17 \mu \mathrm{M}$ \\
\hline Decenolylcarnitine (C10:1) & $0.11 \mu \mathrm{M}$ & $<0.10 \mu \mathrm{M}$ \\
\hline Tetradecadienolycarnitine (C14:1) & $0.06 \mu \mathrm{M}$ & $<0.12 \mu \mathrm{M}$ \\
\hline
\end{tabular}

* Measurements of items considered most relevant to BVVL/FL or known functions of TNFSF13B are reported in the Table. Blood biochemistry including sugar, cholesterol, and triglyceride levels were within normal range. Thyroid hormone measurements were normal. Levels of amino acids associated with metabolic disorders were normal. CD4 and CD8 are, respectively markers for helper and cytotoxic T-cells, and CD19 is a B-cell marker. Percent of cells with T cell and B cell markers were assessed by flow cytometry. $\mathrm{CH} 50$ is an index for totalcomplement level. Anti- nuclear antibody was assessed by fluorescent microscopy. 
Table S5- Conservation of amino acids affected by missense mutations in SLC52A3, SYCP1, VCAN, BAIAP2, and WDFY4 found in BVVL patients*

\begin{tabular}{|c|c|c|c|c|c|c|c|c|}
\hline $\mathrm{m}$ & ID** & & & & SLC52A3 & & & \\
\hline & & p.Gly13Arg & p.Asn21Ser & p.Arg212Cys & p.Ala312Val & p.Tyr329Cys & p.Pro385Ala & p.Leu429Phe \\
\hline Homo sapiens (human) & NP_001357014.1 & LVCVFGMGSWV & SWVTI NGLWVE & SHLESRYLPAH & VAFVN & YSCLS & IAVMSPCPLLQ & RSALLWCGA \\
\hline Pan troglodytes (chimpanz & XP_016792755.2 & LVCVFG & VVE & $\mathrm{AH}$ & GV & & MAVI & ICGA \\
\hline Pongo abelii (orangutan) & XP_024094639.1 & $\operatorname{LVCIF}$ & SWVTI & & GGV & & & ICGA \\
\hline Macaca mulatt & _001181490.1 & sswv & swVtı $\mathbf{N}$ & PAH & VAFVN & YSCLS & MAVM & CGA \\
\hline Bos taurus (cow) & _001014864.1 & swv & swval $\mathbf{N}$ & PAN & VAFVNA & DAY & $M Q$ & VCGA \\
\hline Mus Musculus (m & _081448.2 & wV & SWVAI I & WHOL & VAFVNA & VAY & MAAM & NCGA \\
\hline Rattus norvegi & NP_001032275.1 & swV & SWVAI I & WHLE & VAFVNA & YSCLP YGPVAY & MAAM & NCGA \\
\hline Cricetul & XP_027277327.1 & wv & sWVAl & WHLE & VAFVN & YSCLP & MAAM & VCGA \\
\hline Oryctolagus cuniculus (rabbit) & XP_008254402.1 & LVCTFGMGSWV & SWVAi NGLWVE & GHLQSRYLPAR & VAFVNALTNSV & YSCLS YGTVAY & MAVMSPCPLMQ & RSRSALLWCGA \\
\hline Lonchura striata domestica (fin & XP_031362383.1 & LACAFGMGSWV & SWVAl NGLWVE & FHMESRYLPPN & IAWVSALTNGV & YSCLP YGHTTY & IAVMSI & WYGV \\
\hline Parus major (great tit) & XP_015502662.1 & LACAFG & sWVal NGLWVE & FQLE & ITWVSALTNGV & YSCLP & IAVMS & WYGV \\
\hline Ictalurus & XP_017323199.1 & LACA & SWVA & FTLE & VVCVNCATNGL & FSCMP & MAVMSI & WCGA \\
\hline & & & & & & & & \\
\hline & 47.1 & swv & SWVSI NGLWVE & PPN & VLWVNS & FSCMPYGNMAY & MAAM: & NCGA \\
\hline
\end{tabular}

\begin{tabular}{|c|c|c|c|c|c|c|c|c|}
\hline \multirow[t]{3}{*}{ Organism } & \multicolumn{2}{|c|}{ SYCP1 } & \multicolumn{2}{|c|}{ VCAN } & \multicolumn{2}{|c|}{ BAIAP2 } & \multicolumn{2}{|c|}{ WDFY4 } \\
\hline & Sequence ID** & Mutation & Sequence ID** & Mutation & equence ID** & Mutation & equence ID** & Mutation \\
\hline & & p.Glu640Lys & & p.Thr1213Ala & & p.Arg539Trp & & p.Ser2951Thr \\
\hline Homo sapiens (human) & NP_001269470.1 & QLNVYEIKVNK & NP_004376.2 & P - - EATEKSHF & NP_059345.1 & QGPEGREHGDG & NP_065996.1 & TTIVTSGTSTW \\
\hline Pan troglodytes (chimpanzee) & XP_016780604.1 & QLNVYEIKVNK & XP_517667.3 & P - - EATEKSHF & XP_016788608.1 & $S \ldots \ldots$ & XP_016773727.2 & TTIVTSGTSTW \\
\hline Pongo abelii (orangutan) & XP_002810439.1 & QLNVYEIKVNK & - & - & XP_024090488.1 & PGPEGGEHGDG & XP_024109991.1 & TMIVTCGTSTW \\
\hline Macaca mulatta (m & XP_028685959.1 & QLNVYEIKVNK & XP_001112269.2 & P.- EATEKSHF & XP_014976021.1 & QGPEGREHGDG & XP_015002478.2 & TMIVTSGTSTW \\
\hline Bos taurus (cow) & XP_024845781.1 & QLNVYEIKVNK & NP_851378.1 & P.- EVTEKSHF & XP_010814760.1 & - & NP_001192874.3 & TTIIT AGTSAW \\
\hline Mus Musculus (mouse) & NP_035646.2 & QLNAYEIKVSK & NP_001074718.1 & P. - EAPGKSHS & NP_001032844.2 & s..... & XP_011243421.1 & TMIVTSGASAM \\
\hline Rattus norvegicus (rat) & NP_036942.1 & QLNAYEIKVNK & NP_001164029.1 & P - - EATGKSYS & NP_476544.1 & ............ & XP_008769381.1 & TMIITSGASAW \\
\hline Cricetulus griseus (hamsters) & XP_027249321.1 & QLNAYEIKVNK & XP_027257574.1 & P - - EATEKLHS & XP_027281259.1 & $\ldots$ & XP_003495398.1 & TMIVTSGASAM \\
\hline Oryctolagus cuniculus (rabbit) & XP_008262840.1 & QLNVY & XP_017200054.1 & P - - VATEKPHL & XP_017195899.1 & S ......... & XP_017194119.1 & TTIVTSGASAW \\
\hline Lonchura striata domest & XP_031363384.1 & KANSYEGKVNK & XP_031363370.1 & - & XP_021389776.1 & $S \ldots \ldots$ & XP_031361106.1 & TTIIT $\mathbf{S}$ GTSSW \\
\hline Parus major (great tit) & - & - & XP_015470575.1 & - - - EPAQKILL & XP_015501277.1 & ........... & XP_015489137.1 & TTIIT S GTSSW \\
\hline Ictalurus punctatus (catfish) & XP_017335924.1 & -.... LAK & XP_017307860.1 & - - - DKEVTTIV & AHH41893.1 & ........... & XP_017319576.1 & NVIITAGSSTW \\
\hline Nothobranchius furzeri (killifish) & XP_015814136.1 & KSSQL EVMINK & - & 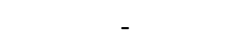 & XP_015806086.1 & $\mathrm{E}-\ldots \ldots$ & XP_015799743.1 & TTLITAGASTW \\
\hline$D a t$ & _001112366.1 & - - VKE & 361.1 & HKLSTNIRIDV & -2 & - & XP_701288.6 & STIITAGTSTW \\
\hline
\end{tabular}

* deletion mutation in TNFSF13B not included: ** from https://www nchinlm nih gov , protein 


\begin{tabular}{ll} 
Table S6- Specifications on exome sequencing data of BVVL-111-II* \\
\hline Total reads & $73,627,784$ \\
Total yield (Mbp) & 7,436 \\
Average read length (bp) & 101.0 \\
Target regions (bp) & $60,456,963$ \\
Average throughput depth of target regions (X) & 123 \\
Initial mappable reads (mapped to human genome) & $73,165,346$ \\
\% Initial mappable reads & 99.3 \\
Non-redundant reads & $65,068,310$ \\
\% Non-redundant reads & 88.9 \\
On-target reads & $47,863,931$ \\
\% On-target reads & 73.5 \\
\% Coverage of target regions (more than 1X) & 99.6 \\
\% Coverage of target regions (more than 10X) & 98.2 \\
\% Coverage of target regions (more than 20X) & 93.4 \\
Mean depth of target regions (X) & 68.3 \\
Number of SNPs & 93,268 \\
Number of synonymous SNPs & 11,731 \\
Number of Missense Variant & 11,116 \\
Number of Stop Gained & 106 \\
Number of Stop Lost & 39 \\
Number of indels & 13,313 \\
Number of Frameshift Variant & 306 \\
Number of Inframe Insertion & 180 \\
Number of Inframe Deletion & 179 \\
Number of \% Found in dbSNP142 & 96.3 \\
Het/Hom Ratio & 1.3 \\
Ts/Tv Ratio & 2.3 \\
\hline & The quality of data pertaining to alindividuals exomed in BVVL \\
\hline & 111 \\
\hline
\end{tabular}

*, The quality of data pertaining to all individuals exomed in BVVL-111, BVVL-103 and FL-101 were similar. 
Table S7- Sequence variations that segregated with BVVL/FL status among family members whose DNAs were exome sequenced *

\begin{tabular}{|c|c|c|c|c|c|c|c|c|c|c|c|c|c|c|}
\hline \multicolumn{5}{|c|}{ BVVL-103 (Proband and unaffected family members $-11,12, \&-112$ were exome sequenced.) } & \multicolumn{5}{|c|}{ BVVL-111 (Proband and unaffected family members - $11,12, \| 1, \&-112$ were exome sequenced.) } & \multicolumn{5}{|c|}{ FL-101 (Proband and unaffected family members - $-11,112, \&$ - -114 - aged 36-43 yrs.- were exome sequenced.) } \\
\hline Chromosome & Gene & $\begin{array}{l}\text { Reference } \\
\text { sequence }\end{array}$ & Variation & Zygosity & & Gene & $\begin{array}{l}\text { Reference } \\
\text { sequence }\end{array}$ & Variation & Zygosity & Chromosome & Gene & $\begin{array}{l}\text { Reference } \\
\text { sequence }\end{array}$ & Variation & Zygosity \\
\hline 1 & SYCP1 & NM_001282541 & c.1918G>A (p.E640K) & Homo & 1 & NCSTN & NM_001290186 & c.757C>T (p.R253W) & Homo & 5 & MCTP1 & NM_001297777 & $c .169 \mathrm{C}>\mathrm{T}(\mathrm{p} . \mathrm{R} 57 \mathrm{X})$ & Het \\
\hline 1 & ANXA9 & NM_003568 & c.938G>A (p.R313K) & Homo & 10 & WDFY4 & NM_020945 & c.8851T>A (p.S2951T) & Homo & & MCTP1 & & c. 770A $>$ G (p.H257R) & Het \\
\hline 5 & VCAN & NM_001164097 & $c .3637 A>G(p . T 1213 A)$ & Homo & 10 & CRTAC1 & NM_001206528 & c.1892A>G (p.Y631C) & Homo & 5 & $A P C$ & NM_001127511 & $c .244 C>T$ (p.L82F) & Het \\
\hline 5 & PCDHGB7 & NM_018927 & c.1469C>T (p.S490F) & Homo & 10 & TCF7L2 & NM_001146283 & c.536C>A (p.P179H) & Homo & & $A P C$ & & c.7891C>T (p.P2631S) & Het \\
\hline \multirow[t]{2}{*}{12} & KNTC1 & NM_014708 & $c .268 \mathrm{G}>\mathrm{C}$ (p.V90L) & Het & 13 & PARP4 & NM_006437 & c.3986C>T (p.P1329L) & Het & 9 & ZNF462 & NM_021224 & c.4922A>C (p.E1641A) & Het \\
\hline & KNTC1 & & c.2911A>G (p.K971E) & Het & & PARP4 & & c.2339A>C (p.K780T) & Het & & ZNF462 & & $\begin{array}{l}\text { c.4905_4906insGAG } \\
\text { (p.T1635delinsTE) }\end{array}$ & Het \\
\hline 17 & BAIAP2 & NM_017451 & c.1615C>T (p.R539W) & Homo & 19 & FOBS & NM_001114171 & c.434C>T (p.P145L) & Homo & 13 & TNFSF13B & NM_001145645 & c.276_281del (p.A93_G94del) & Homo \\
\hline \multirow[t]{5}{*}{$\mathrm{x}$} & ADGRG4 & NM_153834 & c.7637C>G (p.T2546S) & Homo/Hemi & 19 & SLCBA2 & NM_015063 & $c .83 \mathrm{~T}>\mathrm{C}(\mathrm{p} . \mathrm{L} 28 \mathrm{P})$ & Homo & & & & & \\
\hline & & & & & 19 & WDR87 & NM_001291088 & $c .973 G>T(p . E 325 X)$ & Homo & & & & & \\
\hline & & & & & 19 & CPT1C & NM_152359 & $c .2077 \mathrm{C}>\mathrm{A}(\mathrm{p} . \mathrm{L} 693 \mathrm{M})$ & Homo & & & & & \\
\hline & & & & & 19 & IL4I1 & NM_152899 & c.1640G $>A(p .5547 \mathrm{~N})$ & Homo & & & & & \\
\hline & & & & & $x$ & PHEX & NM_000444 & c.1463T >A (p.V488D) & Homo/Hemi & & & & & \\
\hline
\end{tabular}




\begin{tabular}{|c|c|c|c|c|c|c|c|}
\hline Family ID & BVVL-102 & BVVL-104 & BVVL-106 & BVVL-108 & BVVL-109 & BVVL-110 & BVVL-113 \\
\hline Proband ID & BVVL-102-116 & BVVL-104-II1 & BVVL-106-II3 & BVVL-108-II & BVVL-109-II1 & BVVL-110-112 & BVVL-113-IV1 \\
\hline Sex & female & female & female & female & female & female & male \\
\hline Age at examination & 27 yrs & $16 \mathrm{yrs}$ & $17 \mathrm{yrs}$ & $14 \mathrm{yrs}$ & $39 \mathrm{yrs}$ & 41 yrs & $19 \mathrm{yrs}$ \\
\hline Age at onset & $19 \mathrm{yrs}$ & 8 yrs & 9 yrs & 6 yrs & 12 yrs & $14 \mathrm{yrs}$ & 9 yrs \\
\hline Disease duration & 8 yrs & $8 y r s$ & 8 yrs & 8 yrs & $27 \mathrm{yrs}$ & $27 \mathrm{yrs}$ & $10 \mathrm{yrs}$ \\
\hline Initial presentation & dysphagia & hearing problems & dysphagia \& dysarthria & ptosis & hearing problems & hearing problems & asymmetrical facial weakness \\
\hline \multirow[t]{2}{*}{ Bulbar palsy $(\mathrm{CN}-9,12)$} & + & + & + & + & + & + & + \\
\hline & $\begin{array}{l}\text { dysphagia, dysarthria, } \\
\text { tongue atrophy }\end{array}$ & $\begin{array}{l}\text { dysphagia, dysarthria, } \\
\text { tongue atrophy }\end{array}$ & $\begin{array}{l}\text { dysphagia, dysarthria, } \\
\text { severe tongue atrophy }\end{array}$ & $\begin{array}{l}\text { dysphagia, dysarthria, } \\
\text { tongue atrophy }\end{array}$ & $\begin{array}{l}\text { dysphagia, dysarthria, } \\
\text { tongue atrophy }\end{array}$ & dysphagia, dysarthria & $\begin{array}{l}\text { mild dysphagia, dysarthria, } \\
\text { tongue atrophy }\end{array}$ \\
\hline CN-5 palsy & mastication problems & mastication problems & mastication problems and atrophy & mastication problems and atrophy & mastication problems & mastication problems & mastication problems and atrophy \\
\hline Facial weakness (CN-7) & $\begin{array}{l}\text { weakness, atrophy, } \\
\text { fasciculation }\end{array}$ & weakness, atrophy & weakness, atrophy & severe weakness, atrophy & weakness, atrophy & $\begin{array}{l}\text { weakness, atrophy } \\
\text { fasciculation }\end{array}$ & weakness, atrophy \\
\hline Hearing problem (CN-8) & + & + & + & + & + & + & + \\
\hline Ophthalmoplegia (CN3/4/6 palsy) & & - & & + & - & + & \\
\hline Ptosis & - & - & + & + & - & - & - \\
\hline Optic nerve atrophy (CN-2 involvement) & - & - & - & - & - & - & - \\
\hline Limb weakness & + & - & - & - & $\begin{array}{l}\text { +, symmetrical, > prominent } \\
\text { in distal upper extremities }\end{array}$ & $\begin{array}{l}\text { +, asymmetrical, more } \\
\text { prominent at left side }\end{array}$ & - \\
\hline Limb muscle atrophy & + , distal atrophy & - & - & - & + & + , distal atrophy & - \\
\hline Spasticity & & - & & - & - & & \\
\hline Increased DTR & + & - & - & & + & + in upper extremities & - \\
\hline Decreased DTR & - & - & - & - & - & + in lower extremities & \\
\hline Sensory symptoms/ signs & - & - & - & - & - & - & - \\
\hline Tremor & - & + , hand tremor & - & - & - & - & - \\
\hline Ataxia & - & - & - & - & - & - & - \\
\hline Vertigo & + & - & - & - & - & - & - \\
\hline Tinnitus & - & - & - & - & - & - & - \\
\hline Seizure & & - & - & - & - & & \\
\hline Mental impairment & - & - & - & - & - & - & - \\
\hline Psychiatric disorder & + , depression & + , depression & - & + , depression & + , depression & + , depression & - \\
\hline Autonomic dysfunction & - & - & - & - & - & - & - \\
\hline Upward plantar reflex & - & - & - & - & + & - & - \\
\hline Respiratory problem & - & - & - & - & - & - & - \\
\hline Ambulatory status & no limitation & no limitation & no limitation & no limitation & no limitation & no limitation & no limitation \\
\hline Acylcarnitine profile & not done & not done & not done & not done & not done & not done & not done \\
\hline \multirow[t]{3}{*}{ EMG } & motor neuronopathy, more & motor neuronopathy, more & motor neuronopathy, more & motor neuronopathy & motor neuronopathy, more & motor neuronopathy, more & motor neuronopathy, more \\
\hline & prominent but not restricted & prominent but not restricted & prominent but not restricted & restricted to cranial & prominent but not restricted & prominent but not restricted & prominent but not restricted \\
\hline & to cranial myotomes & to cranial myotomes & to cranial myotomes & myotomes & to cranial myotomes & to cranial myotomes & to cranial myotomes \\
\hline NCS & Normal sensory findings & Normal sensory findings & Normal sensory findings & Normal sensory findings & Normal sensory findings & Normal sensory findings & Normal sensory findings \\
\hline Response to riboflavin & + & + & + & + & + & + & + \\
\hline
\end{tabular}

$\mathrm{CN}$, cranial nerve; DTR, deep tendon reflex; EMG, electromyography; NCS; nerve conduction studies 
Table 2- Clinical data on BVVL/FL probands with mutations in genes other than SLC52A3 or SLC52A2

\begin{tabular}{|c|c|c|c|}
\hline Family ID & BVVL-103 & BVVL-111 & FL-101 \\
\hline Patient ID & BVVL-103-II1 & BVVL-111-II3 & FL-101-II3 \\
\hline Sex & male & male & female \\
\hline Age at examination & 29 yrs & 37 yrs & 39 yrs \\
\hline Age at onset & 11 yrs & $16 \mathrm{yrs}$ & $2 \mathrm{yrs}^{*}$ \\
\hline Disease duration & $18 \mathrm{yrs}$ & $21 \mathrm{yrs}$ & $37 \mathrm{yrs}$ \\
\hline Initial presentation & facial weakness & hearing problem & $\begin{array}{l}\text { asymmetric distal weakness } \\
\text { of lowwer extremities }\end{array}$ \\
\hline Bulbar palsy $(\mathrm{CN}-9,12)$ & $\begin{array}{c}+ \\
\text { dysphagia, dysarthria, } \\
\text { tongue atrophy }\end{array}$ & $\stackrel{+}{+}+$ & - \\
\hline CN-5 palsy & $\begin{array}{l}\text { mastication problems and } \\
\text { masseter muscle atrophy }\end{array}$ & - & $\begin{array}{l}\text { mastication problems and } \\
\text { restriction in opening mouth }\end{array}$ \\
\hline Facial weakness (CN-7) & weakness, atrophy & - & asymmetric weakness, atrophy \\
\hline Hearing problems (CN-8) & + & + & - \\
\hline Ophthalmoplegia (CN3/4/6 palsy) & - & - & - \\
\hline Ptosis & + & - & + \\
\hline Optic nerve atrophy (CN-2 involvement) & - & - & - \\
\hline Limb weakness & $\begin{array}{l}\text { +, asymmetric, } \\
\text { more prominent at right side }\end{array}$ &,+ mild distal \& symmetric & $\begin{array}{l}\text { +, asymmetric, more prominent in right side, } \\
\text { significantly more severe in lower extremities }\end{array}$ \\
\hline Limb muscle atrophy & + , distal atrophy & - & + , distal atrophy \\
\hline Spasticity & - & - & - \\
\hline Increased DTR & - & - & - \\
\hline Decreased DTR & + & - & + in lower extremities \\
\hline Sensory symptoms/ signs & - & - & - \\
\hline Tremor & + , hand tremor & + , hand tremor & + , mild asymmetric (left > right) hand tremor \\
\hline Ataxia & - & + & - \\
\hline Vertigo & - & - & - \\
\hline Tinnitus & - & - & - \\
\hline Seizure & - & - & +, one episode in early childhood \\
\hline Mental impairment & - & - & - \\
\hline Psychiatric disorder & - & - & - \\
\hline Autonomic dysfunction & - & - & - \\
\hline Upward plantar reflex & - & - & - \\
\hline Respiratory problem & - & + & - \\
\hline Ambulatory status & slow but device or help not needed & no limitation & slow, uses braces but does not need help \\
\hline Acylcarnitine profile & not done & normal & normal \\
\hline Brain MRI/CT Scan & normal & normal & normal \\
\hline \multirow[t]{2}{*}{ EMG } & motor neuronopathy, more & motor neuronopathy & motor neuronopathy \\
\hline & $\begin{array}{l}\text { prominent but not restricted } \\
\text { to cranial myotomes }\end{array}$ & $\begin{array}{l}\text { at extremities and } \\
\text { cranial and truncal levels }\end{array}$ & $\begin{array}{l}\text { at extremities and } \\
\text { cranial and truncal levels }\end{array}$ \\
\hline NCS & Normal sensory findings & Normal sensory findings & Normal sensory findings \\
\hline
\end{tabular}

*, no apparent progression between age of 2 yrs. and 16 yrs; CN, cranial nerve; DTR, deep tendon reflex; EMG, electromyography; NCS; nerve conduction studies 
Table 3- Data on SLC52A3 mutations observed in seven BVVL probands

\begin{tabular}{|c|c|c|c|c|c|c|c|c|c|c|c|c|c|}
\hline $\begin{array}{l}\text { Mutation } \\
\text { no. }\end{array}$ & $\begin{array}{l}\text { Proband } \\
\text { ID }\end{array}$ & Sex & $\begin{array}{c}\text { Parental } \\
\text { consanguinity }\end{array}$ & $\begin{array}{c}\text { Het/ } \\
\text { Comp Het/ } \\
\text { Homo }\end{array}$ & $\begin{array}{c}\text { CDNA } \\
\text { variation }\end{array}$ & $\begin{array}{l}\text { Effect on } \\
\text { protein }\end{array}$ & $\begin{array}{l}\text { PolyPhen } \\
\text { prediction }\end{array}$ & $\begin{array}{c}\text { SIFT } \\
\text { prediction }\end{array}$ & $\begin{array}{l}\text { PROVEAN } \\
\text { prediction }\end{array}$ & $\begin{array}{c}\text { Novel/ } \\
\text { non-novel }\end{array}$ & $\begin{array}{l}\text { Report in } \\
\text { data bases }\end{array}$ & $\begin{array}{c}\text { Earlier } \\
\text { publication }\end{array}$ & $\begin{array}{l}\text { Present/ } \\
\text { absent in } \\
\text { controls }\end{array}$ \\
\hline 1 & BVVL-102-116 & $\mathrm{F}$ & & Comp Het & $c .62 A>G$ & p.Asn21Ser & probably damaging & affected protein function & deleterious & non-novel & $\begin{array}{c}\text { dbSNP: rs199588390 } \\
\text { HGMD: CM128722 }\end{array}$ & $\begin{array}{l}\text { PMID: } 27702554 \\
\text { PMID: } 22718020\end{array}$ & absent \\
\hline 2 & & & & & $c .935 \mathrm{C}>\mathrm{T}$ & p.Ala312Val & probably damaging & affected protein function & deleterious & non-novel & HGMD: CM128724 & PMID: 22718020 & absent \\
\hline 3 & BVVL-104-II1 & $\mathrm{F}$ & + & Homo & c. $11153 \mathrm{C}>\mathrm{G}$ & p.Pro385Ala & probably damaging & affected protein function & deleterious & novel & & & absent \\
\hline 4 & BVVL-106-II3 & $\mathrm{F}$ & + & Homo & c. $634 \mathrm{C}>\mathrm{T}$ & p.Arg212Cys & benign & tolerated & neutral & non-novel & dbSNP: rs778479139 & PMID: 29053833 & absent \\
\hline 5 & BVVL-108-II1 & $\mathrm{F}$ & + & Homo & $c .1285 C>T$ & p.Leu429Phe & probably damaging & affected protein function & deleterious & novel & & & absent \\
\hline 6 & BVVL-109-II1 & $\mathrm{F}$ & - & Het & $c .986 \mathrm{~A}>\mathrm{G}$ & p.Tyr329Cys & probably damaging & affected protein function & deleterious & novel & & & absent \\
\hline 1 & BVVL-110-II2 & $\mathrm{F}$ & + & Homo & $c .62 A>G$ & p.Asn21Ser & probably damaging & affected protein function & deleterious & non-novel & $\begin{array}{l}\text { dbSNP: rs199588390 } \\
\text { HGMD: CM128722 }\end{array}$ & PMID: 27702554 & absent \\
\hline 7 & BVVL-113-IV1 & M & + & Het & $c .37 \mathrm{G}>\mathrm{A}$ & p.Gly13Arg & probably damaging & affected protein function & deleterious & non-novel & dbSNP: rs146302587 & PMID: 29053833 & absent \\
\hline
\end{tabular}

$\mathrm{M}$, male; F, female; Het, heterozygous; Comp.Het, compound heterozygous; Homo, homozygous. 
BVVL 102

I

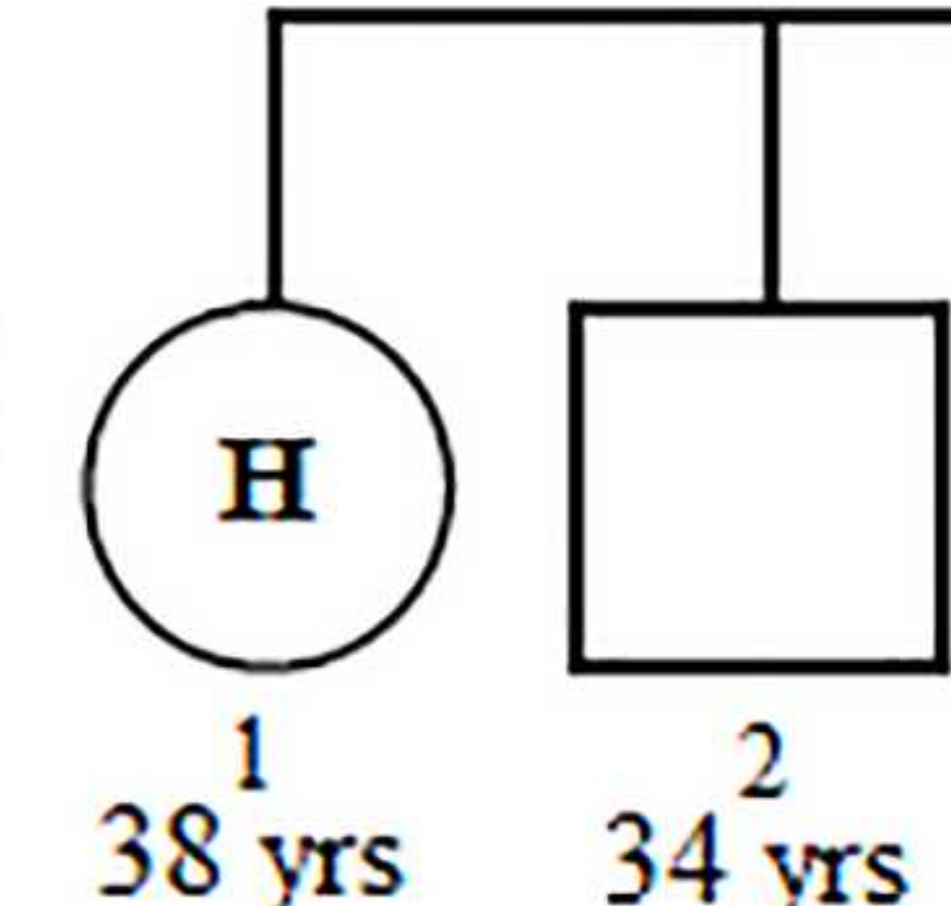

38 yrs 34 yrs $33^{3}$ yrs

BVVL 108

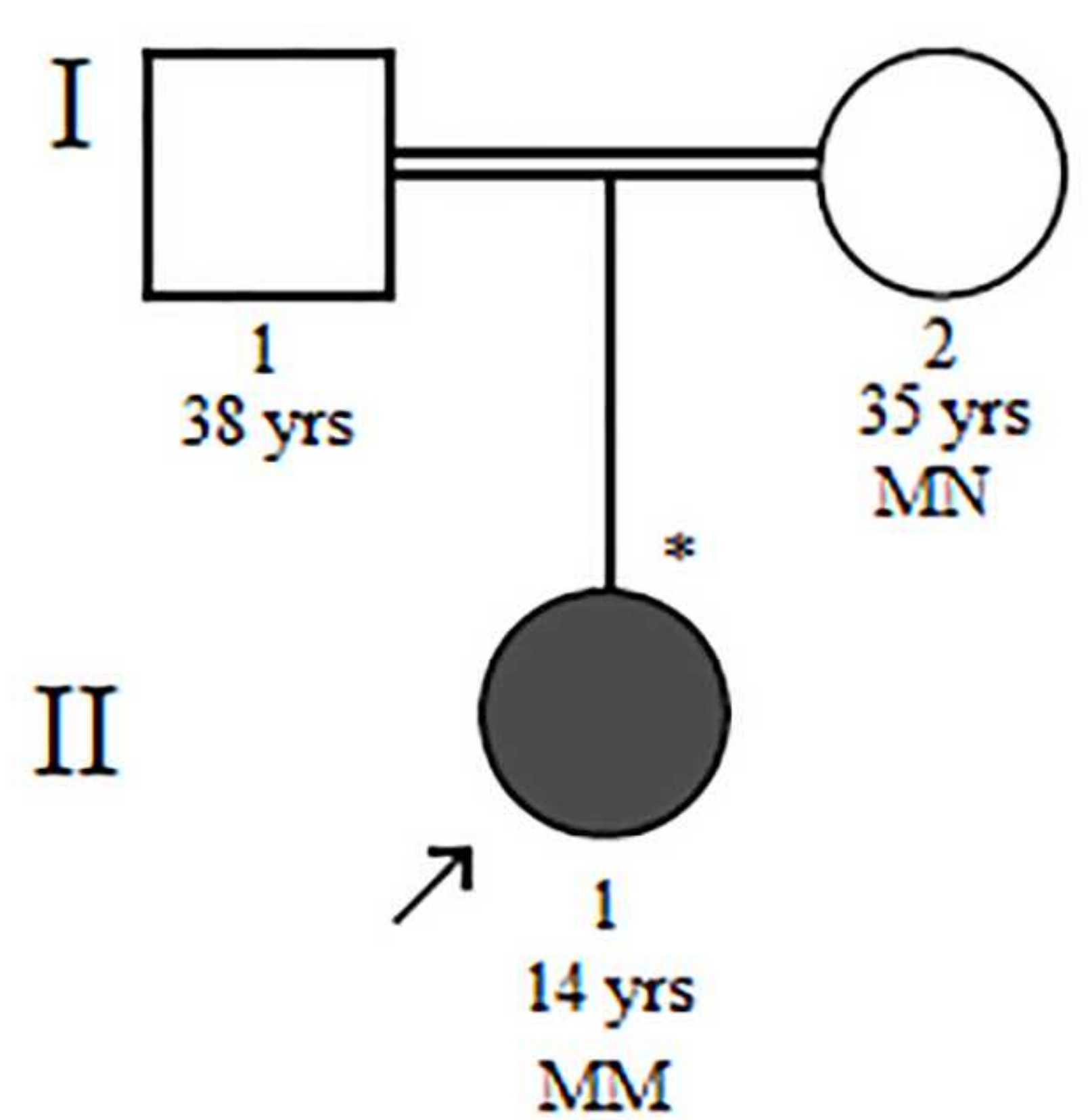

BVVL 104

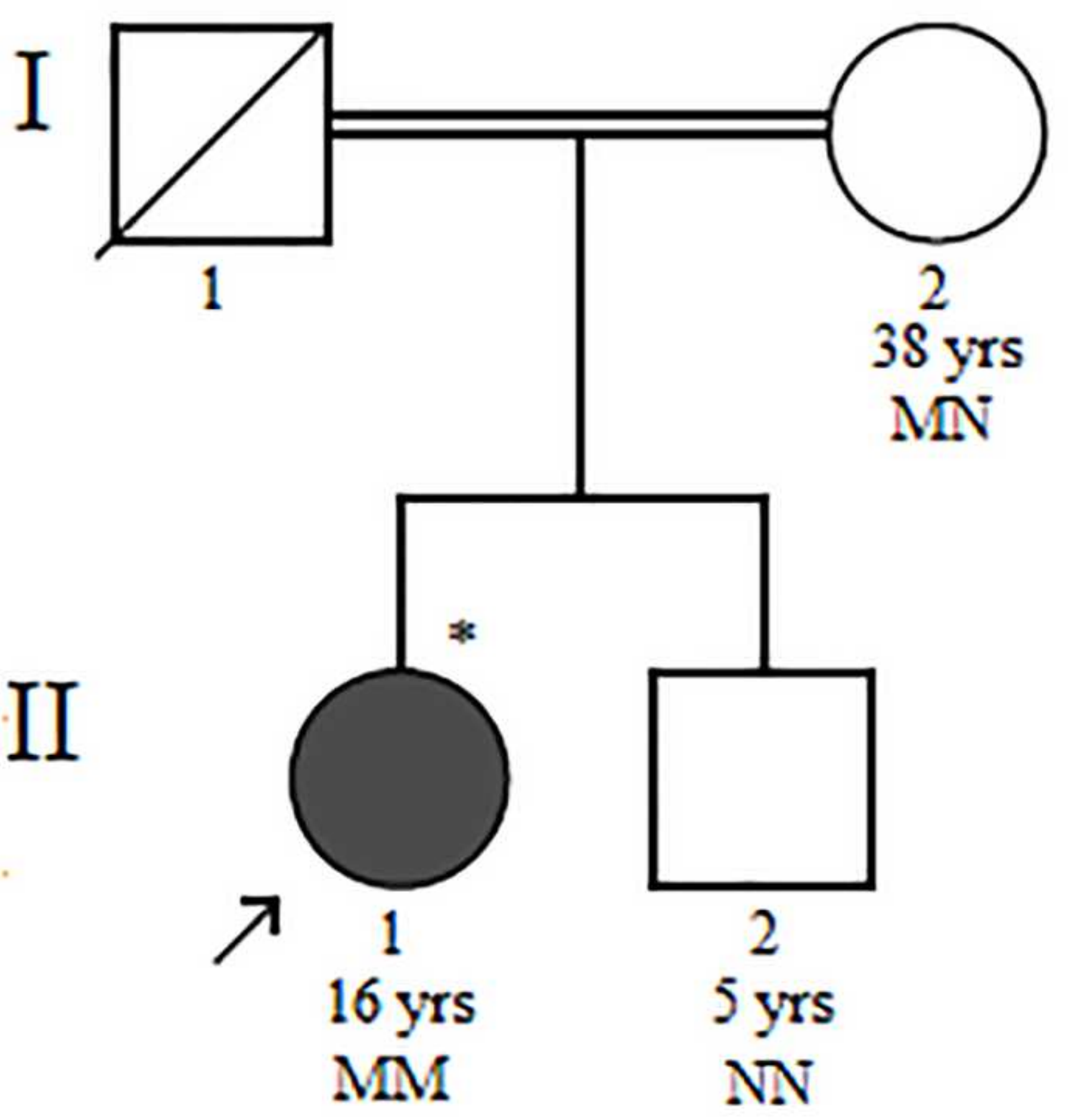

BVVL 106

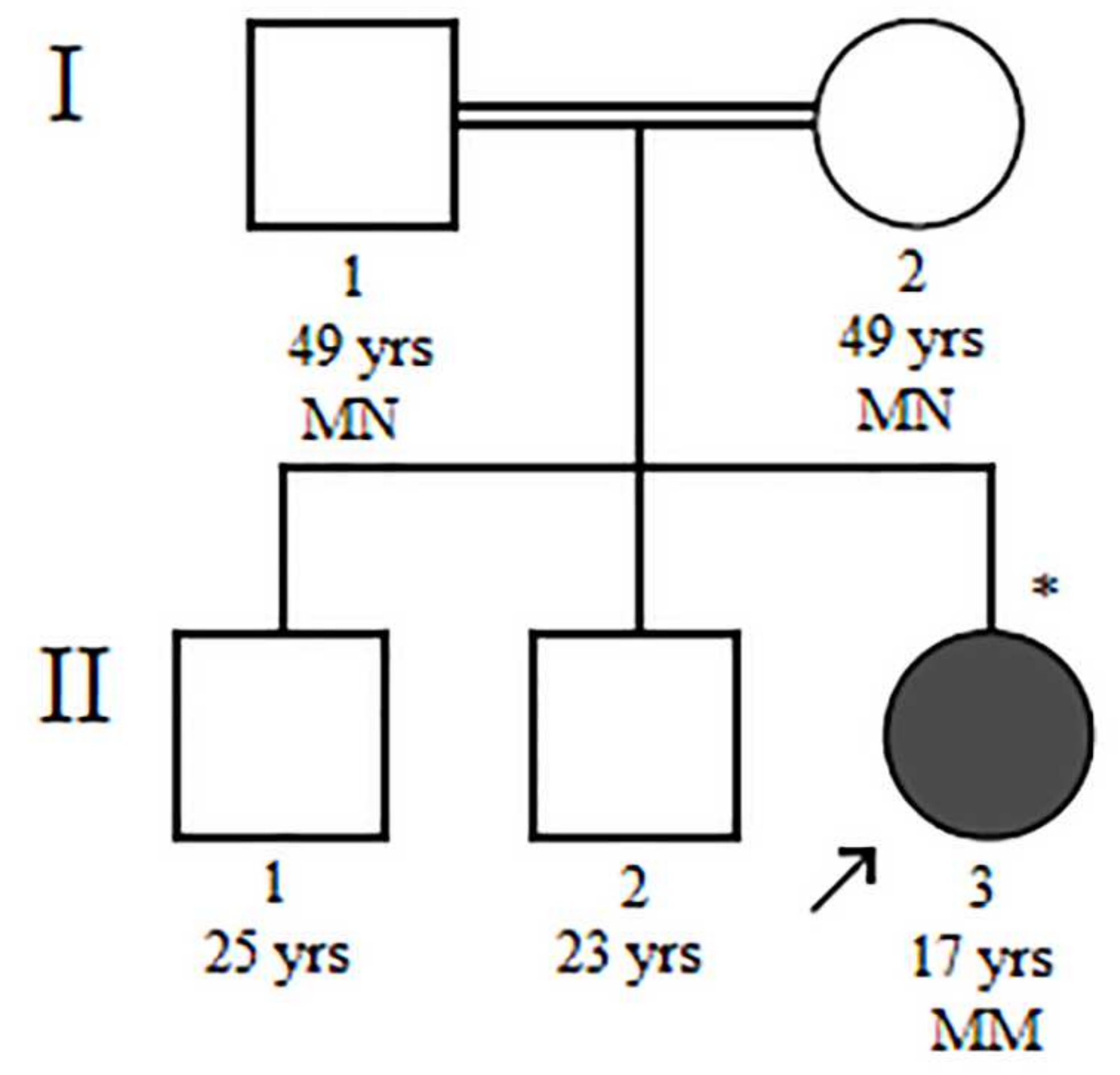

BVVL 113

I

II

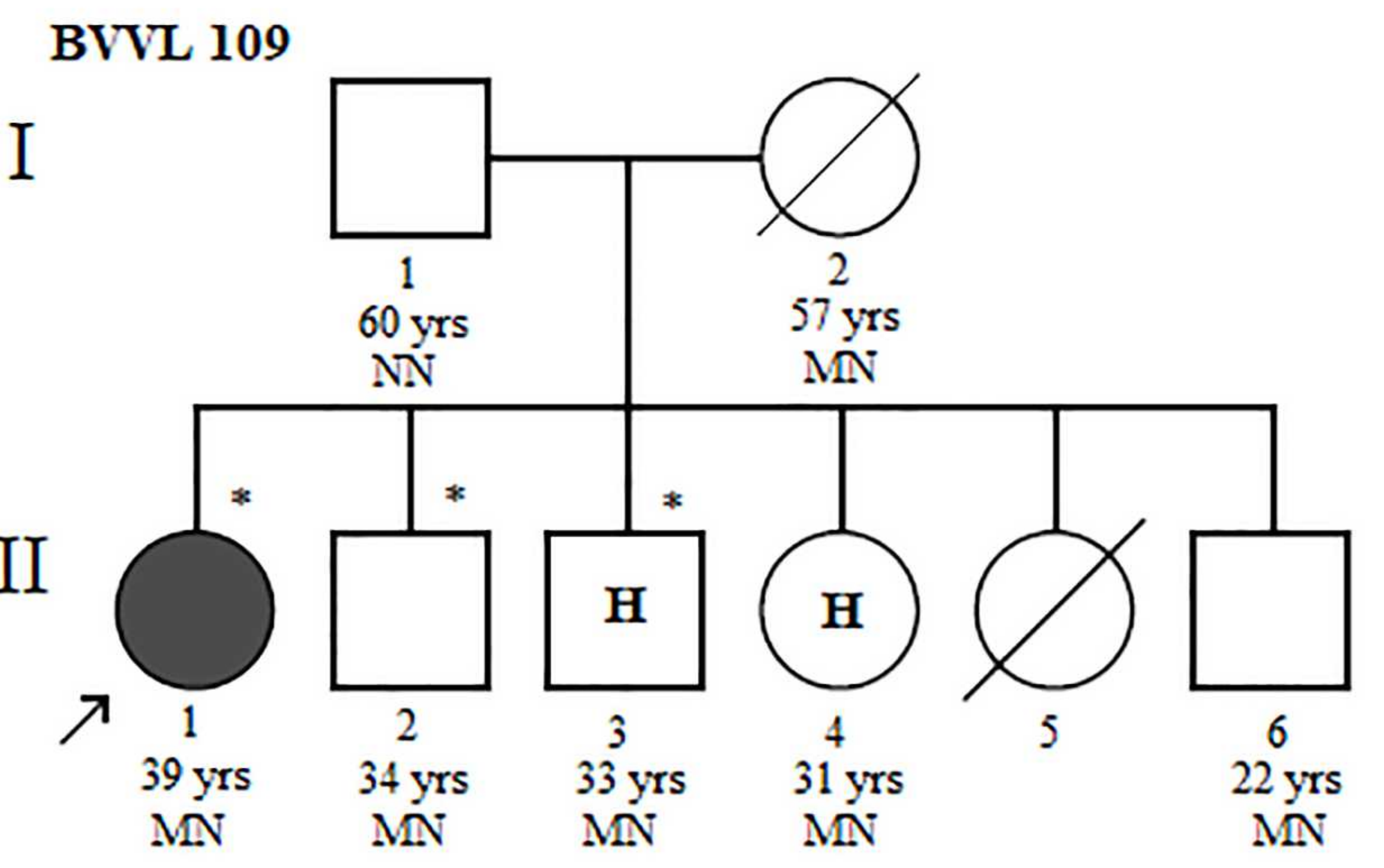

BVVL 110
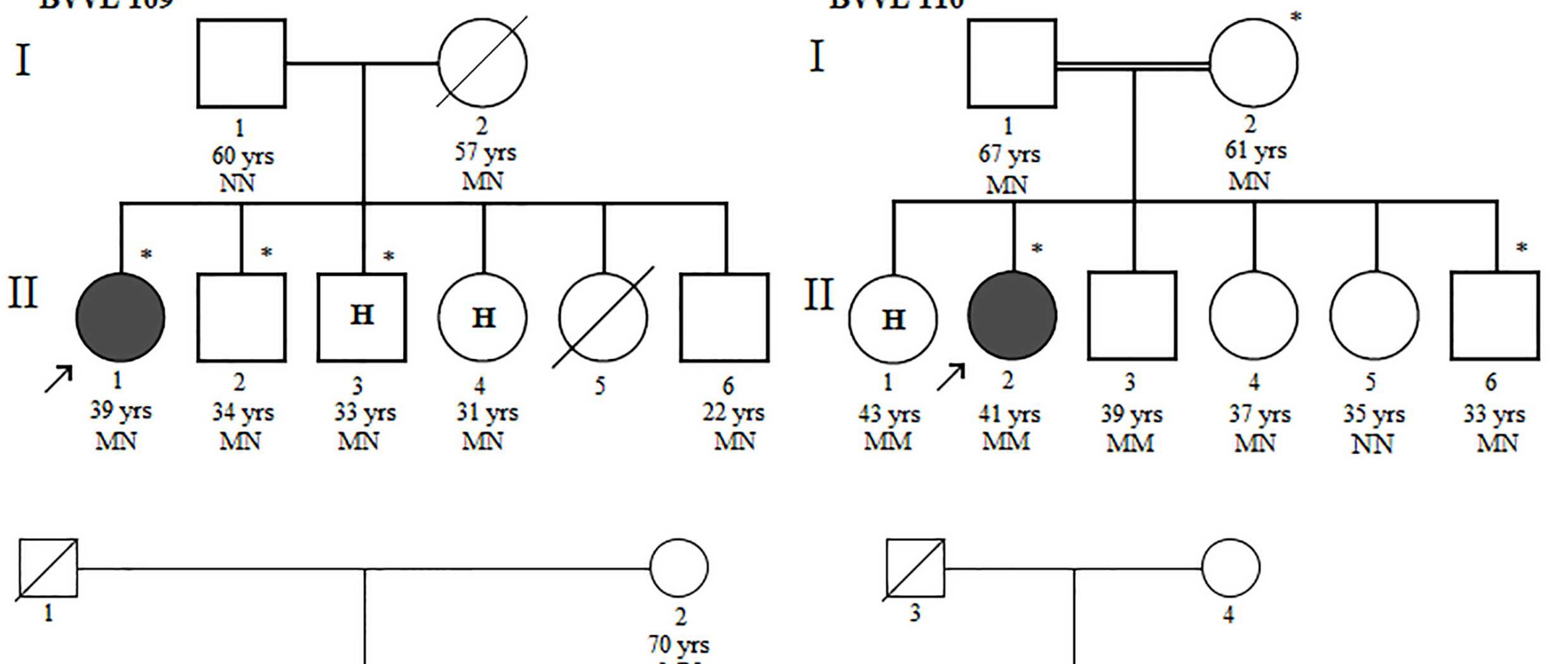

II

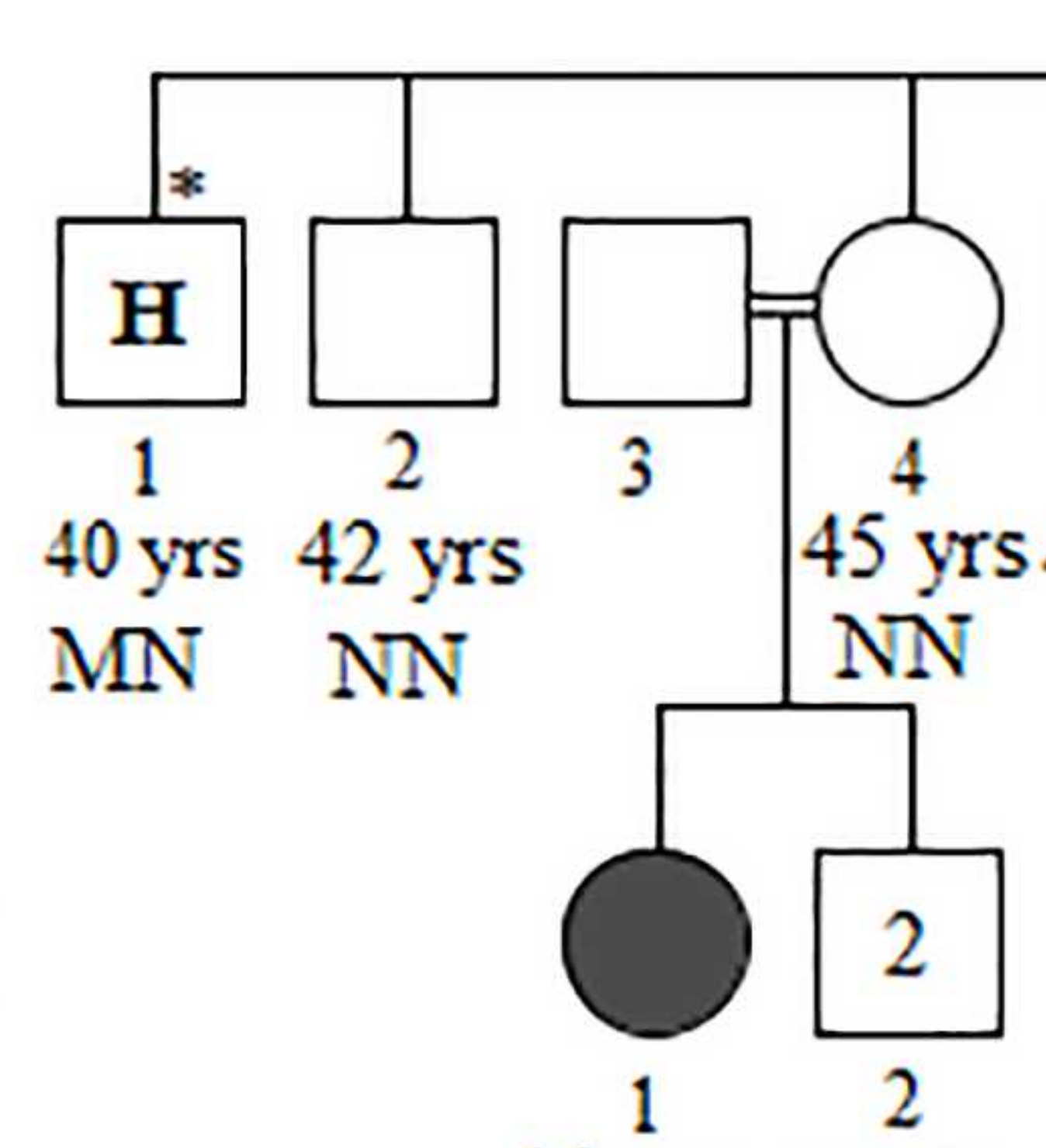

29 yrs $24,21 \mathrm{yrs}$

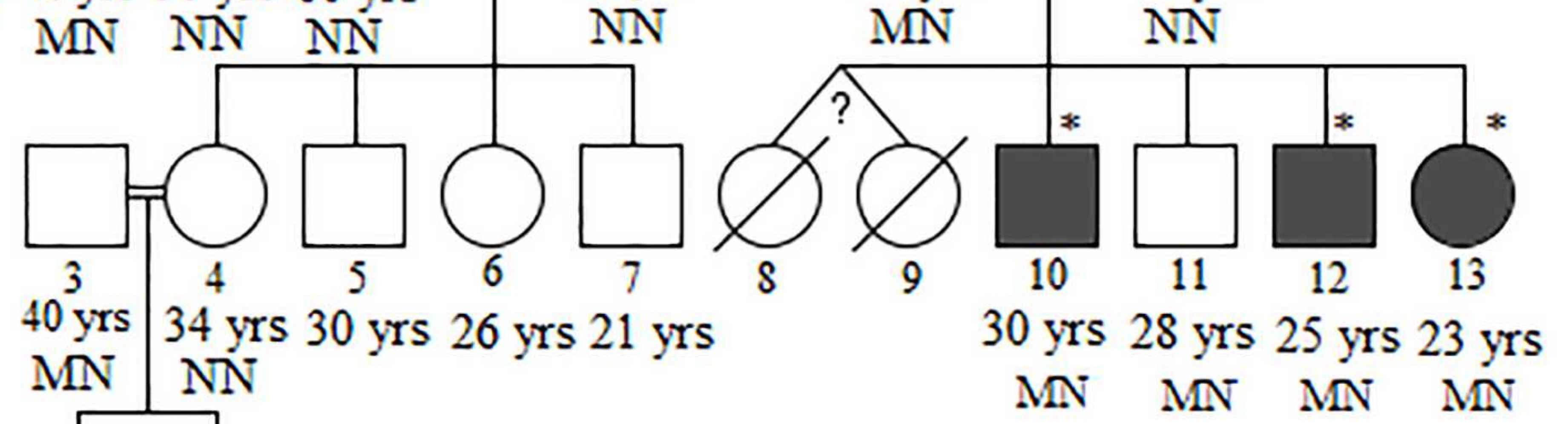

IV
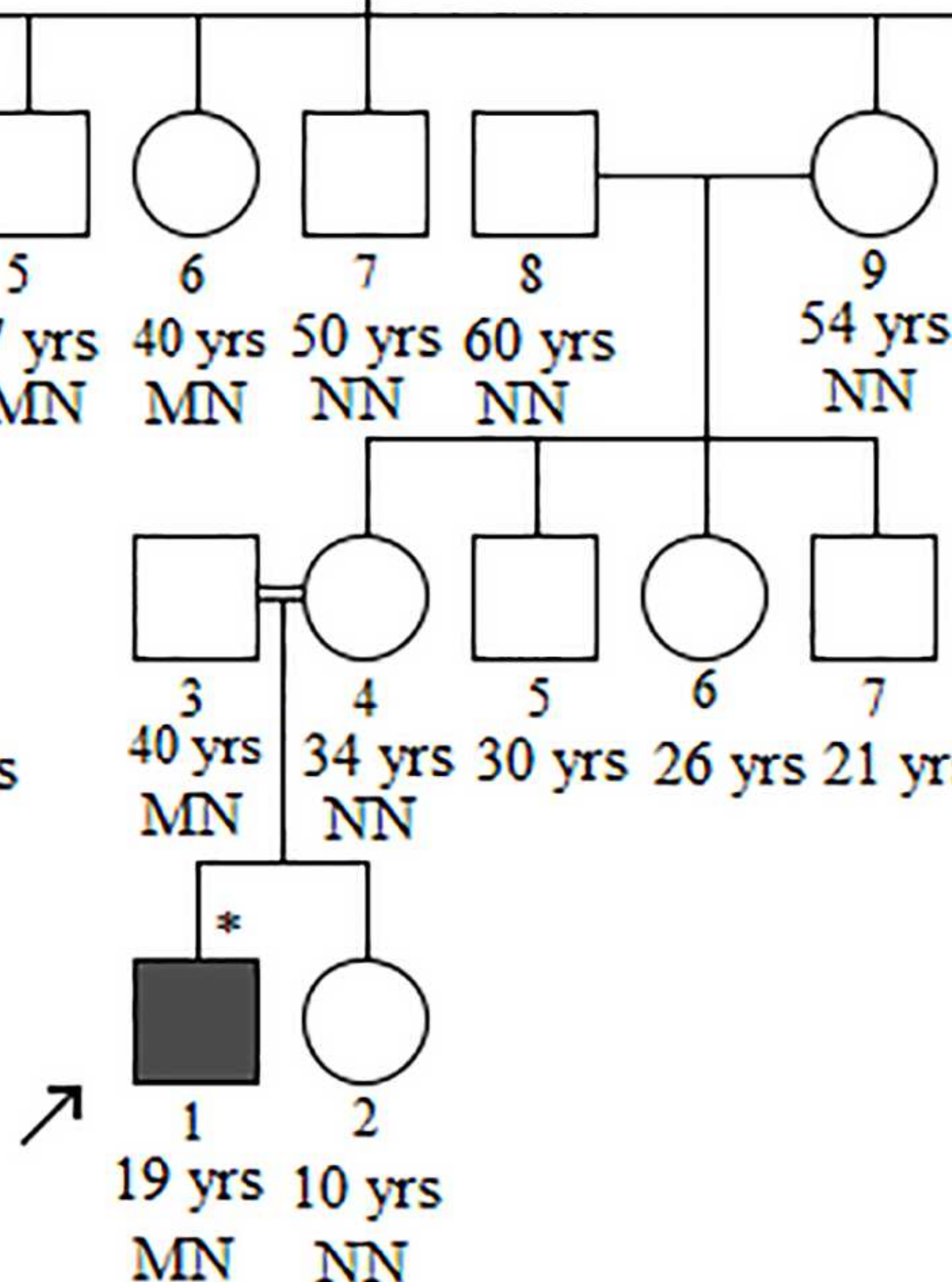

MN

B

BVVL 103

I

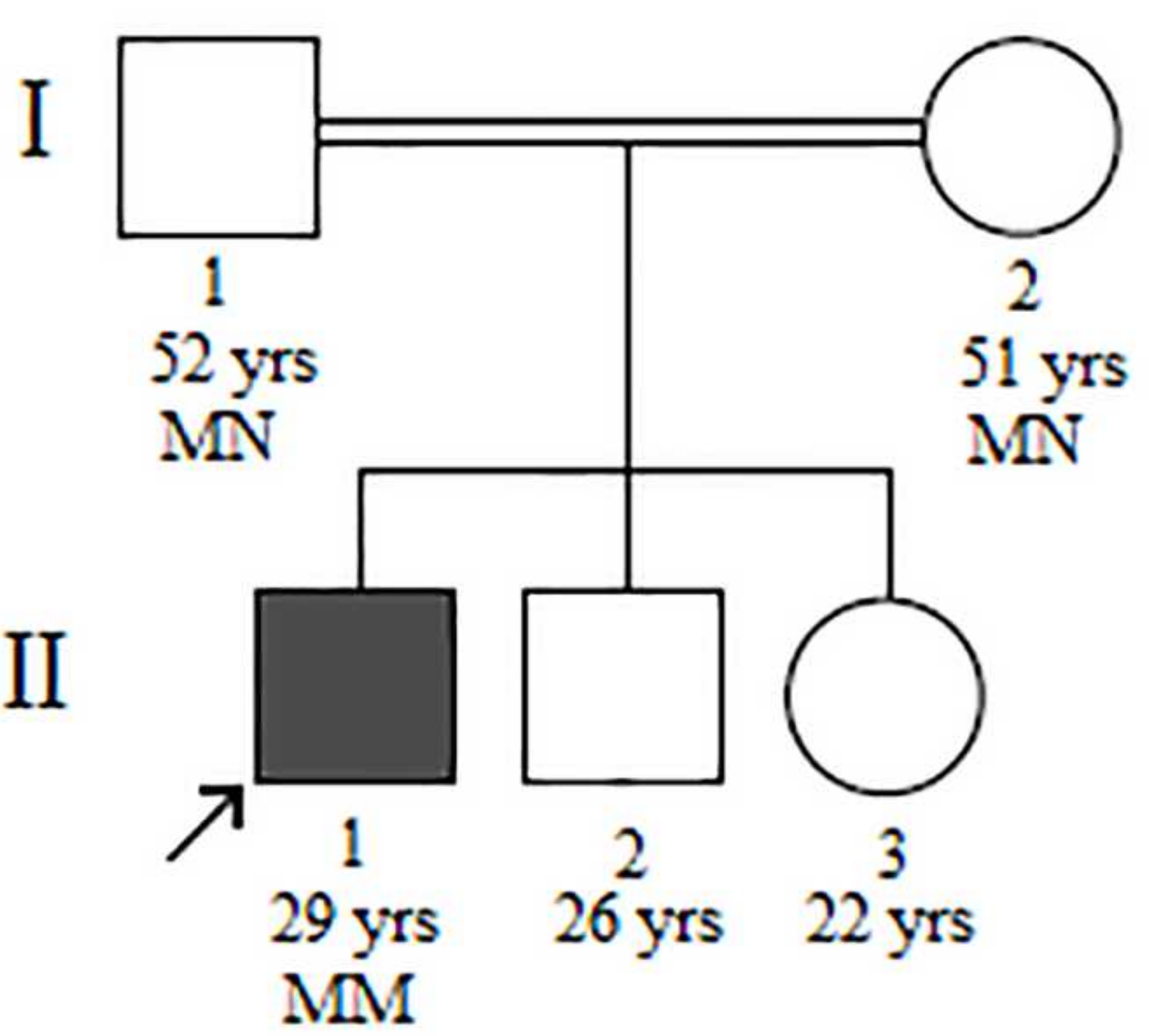

BVVL 111

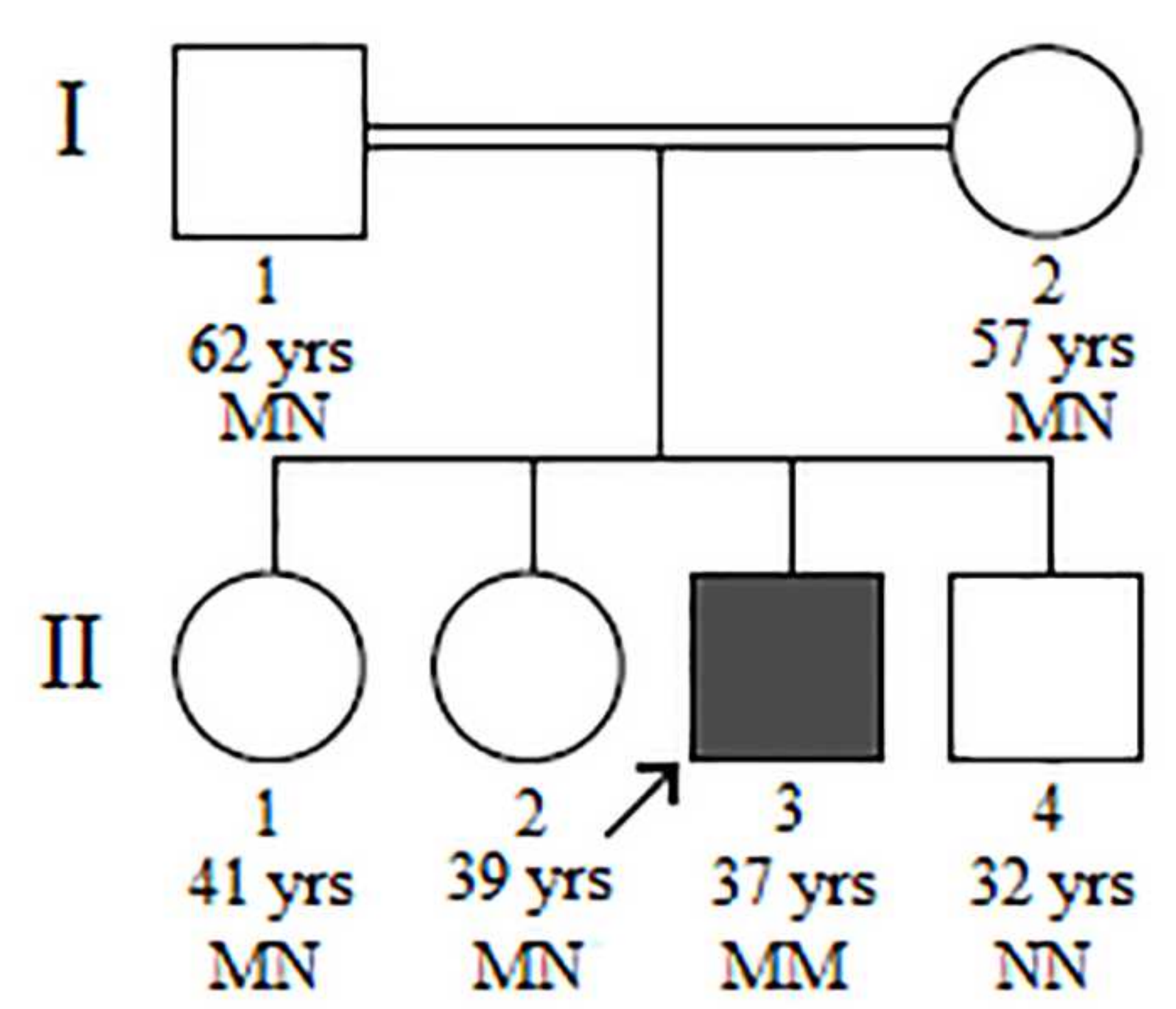

FL 101

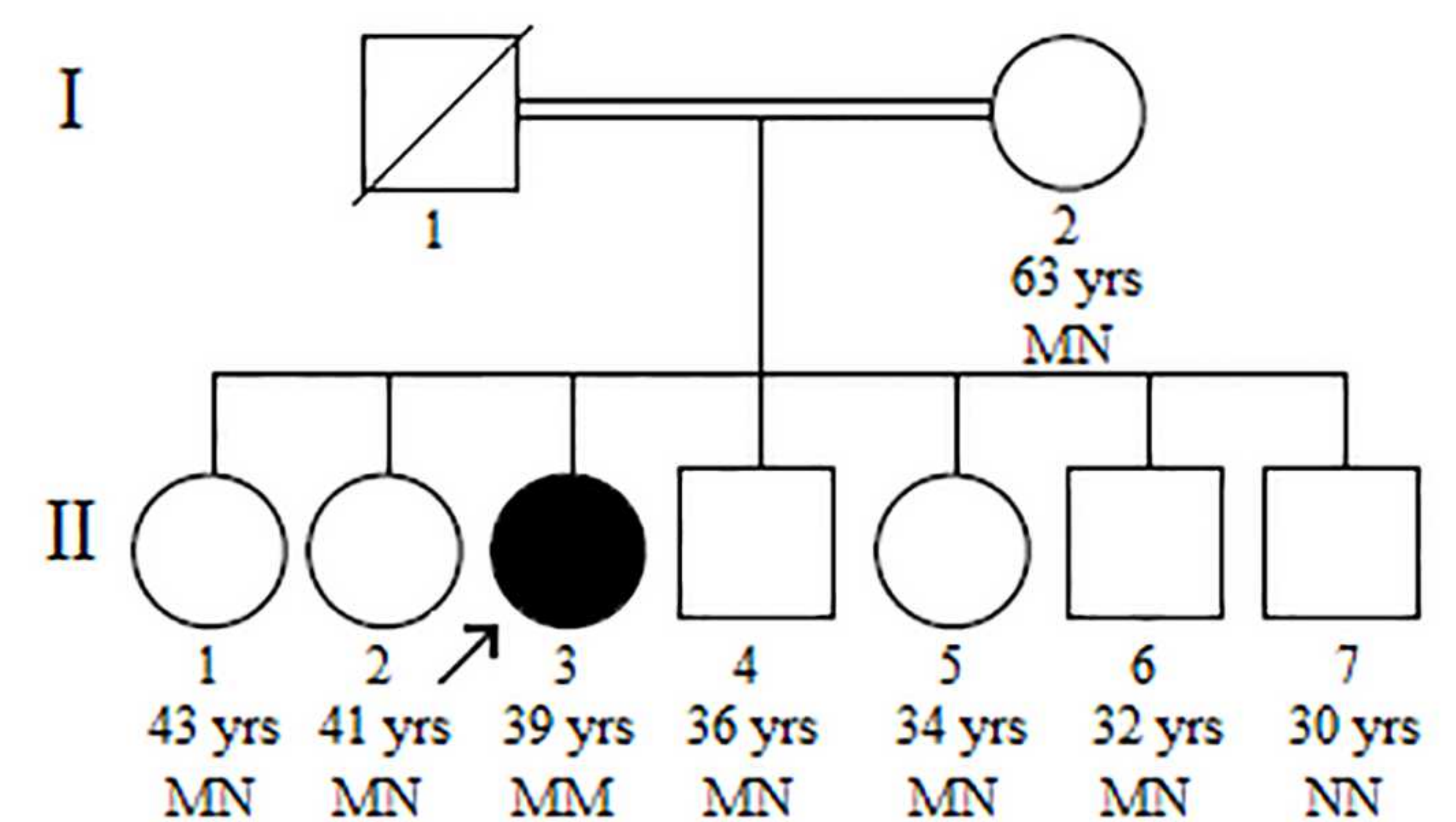




\section{SYCP1}

c.1918G>A; p.Glu640Lys BVVL 103

\begin{tabular}{llllllllllllll}
$G$ & $T$ & $T$ & $T$ & $A$ & $T$ & $A$ & $A$ & $G$ & $A$ & $T$ & $A$ & $A$ \\
\hline
\end{tabular}

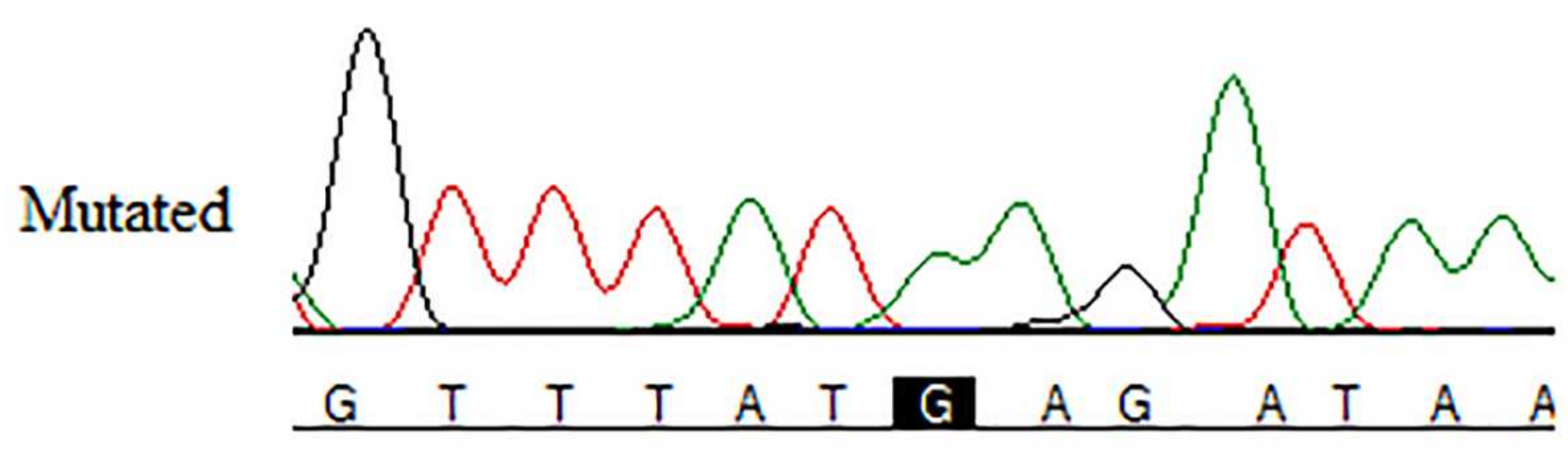

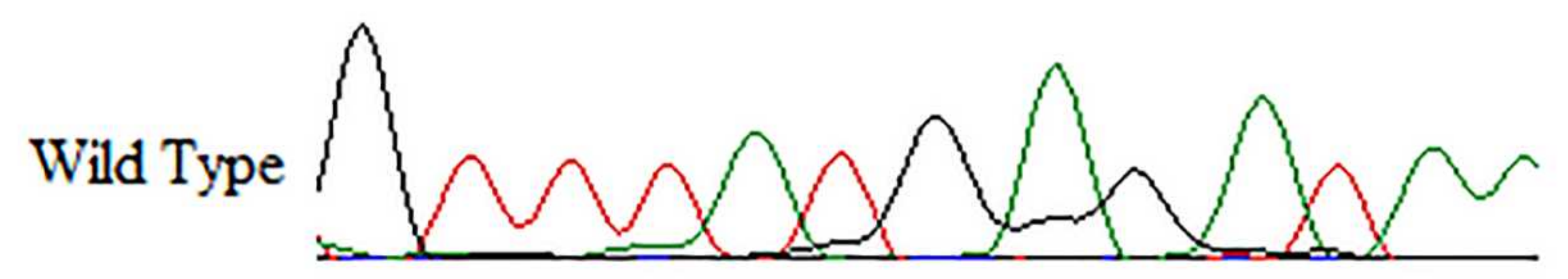

\section{VCAN}

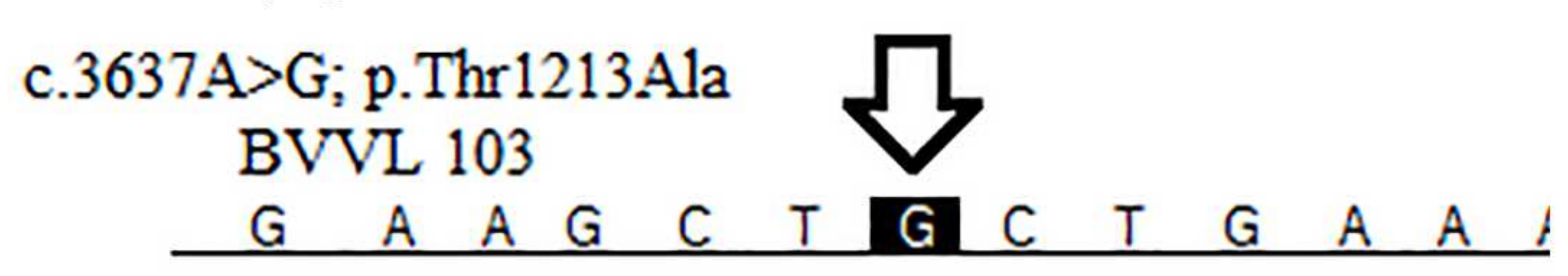

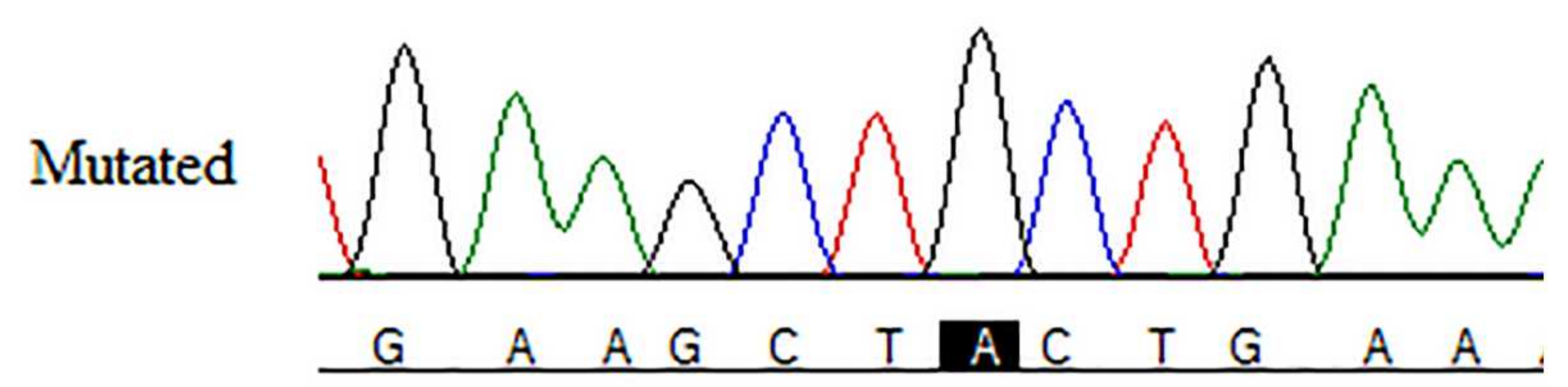

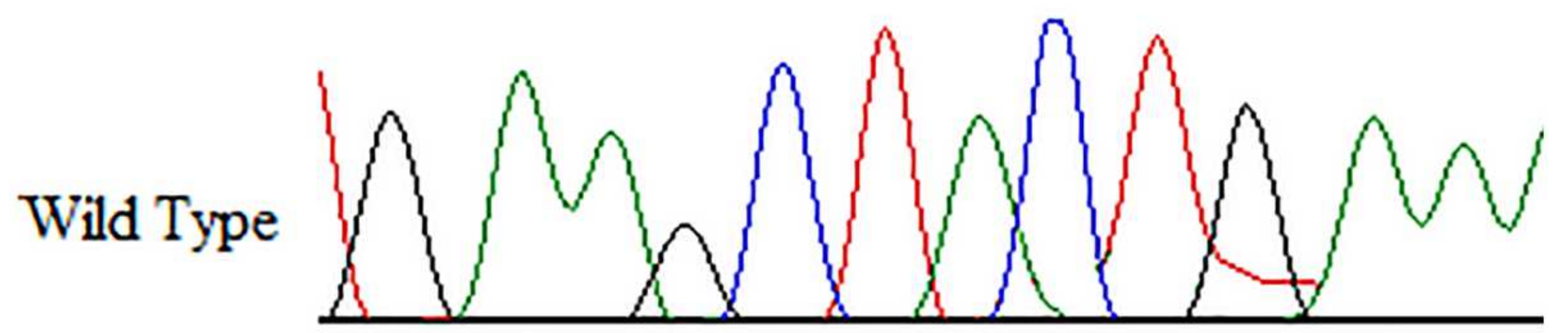

\section{BAIAP2}
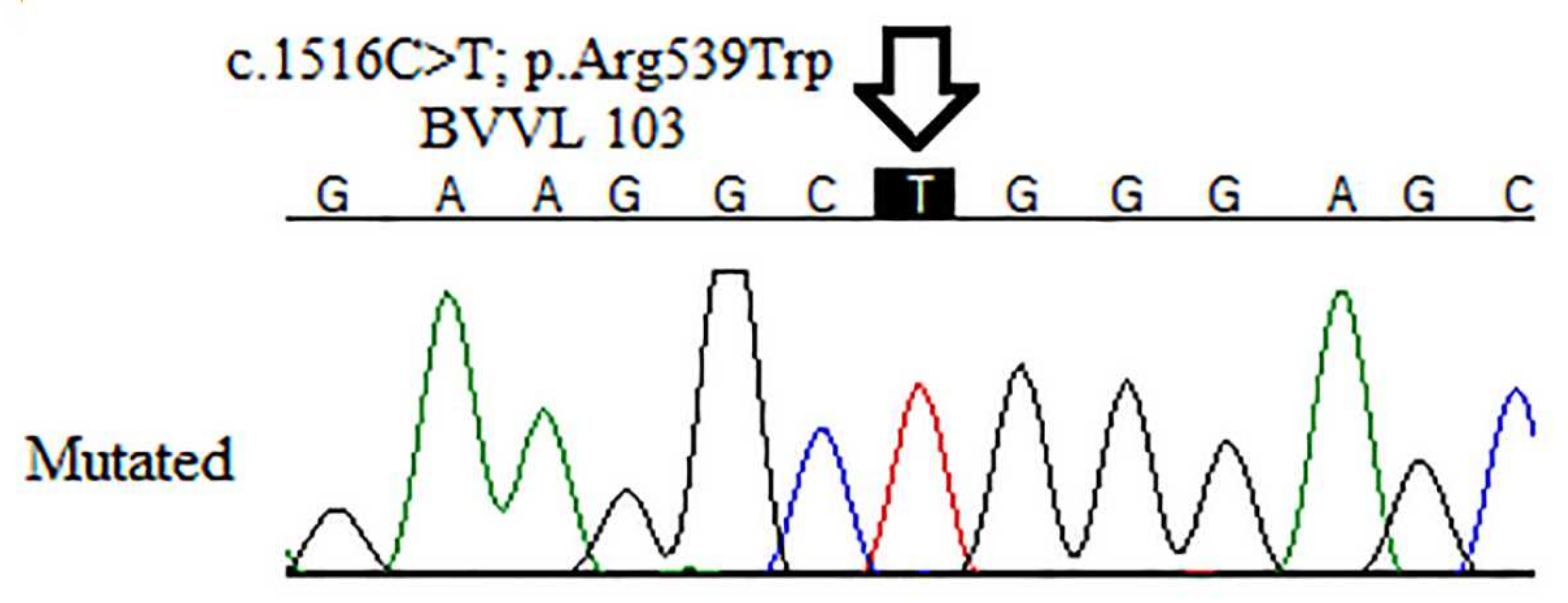

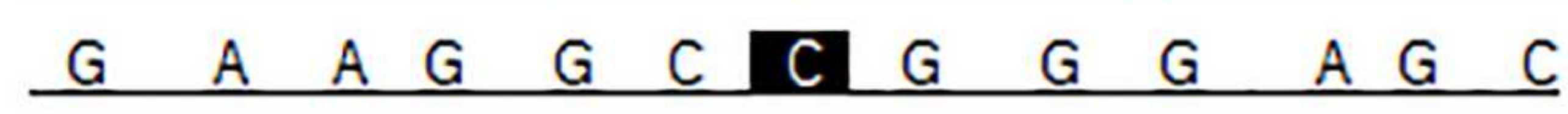

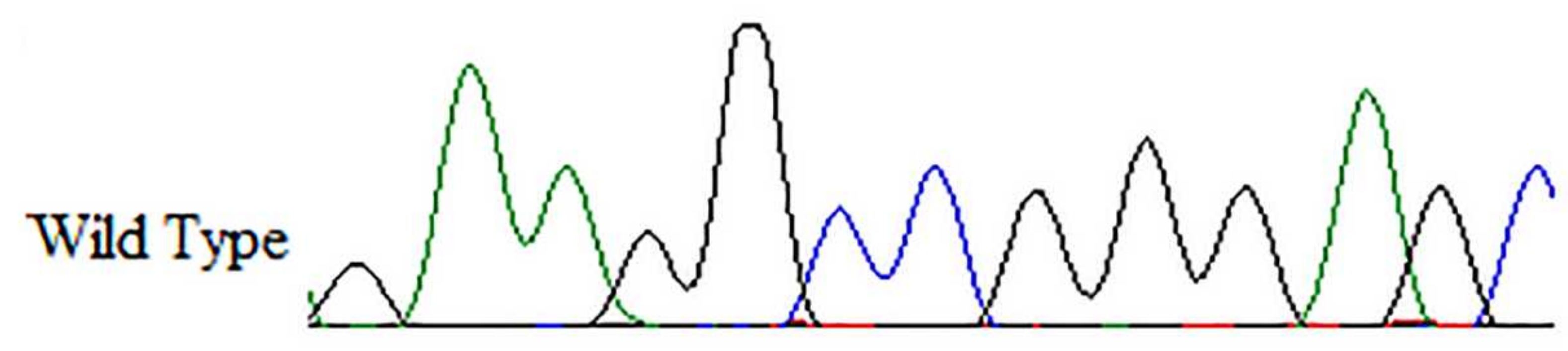

\section{WDFY4}

c. $8851 \mathrm{~T}>\mathrm{A} ; \mathrm{p} . \mathrm{Ser} 2951 \mathrm{Thr}$

BVVL 111

\begin{tabular}{lllllllllllll}
$G$ & $T$ & $C$ & $A$ & $C$ & $C$ & $A$ & $C$ & $T$ & $G$ & $G$ & $G$ \\
\hline
\end{tabular}

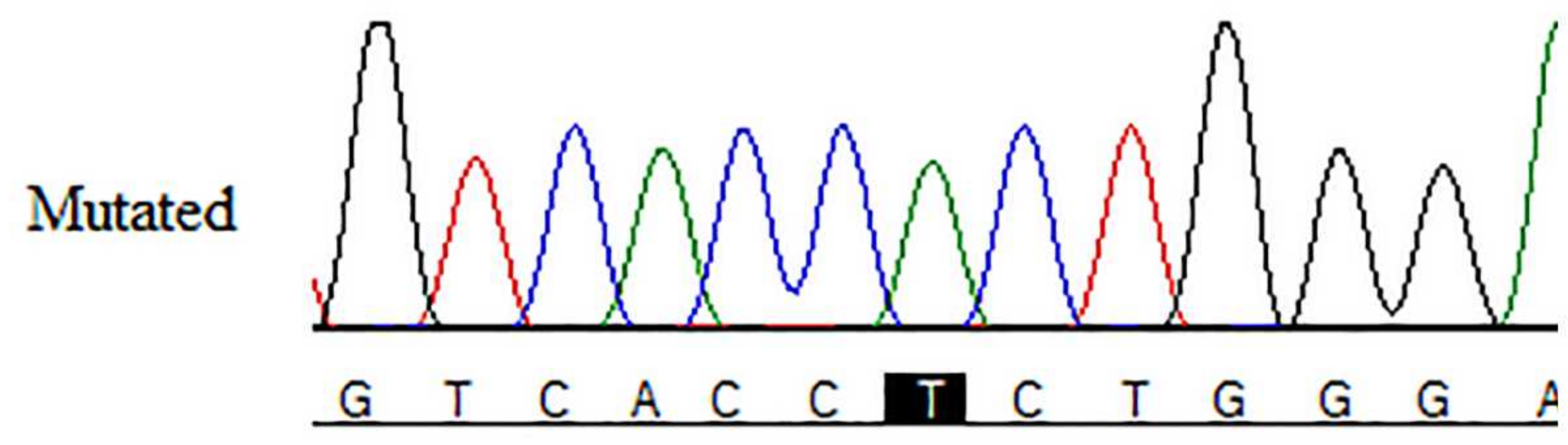

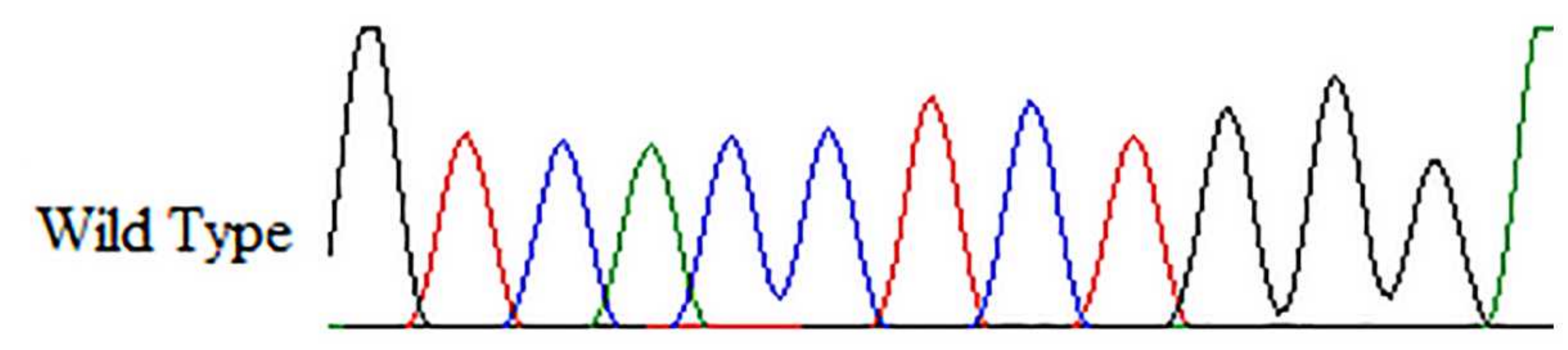

\section{TNFSF13B}

c.276_281del; p.A93_G94del

C T GC CA $G=M \quad G \quad R \quad G C$

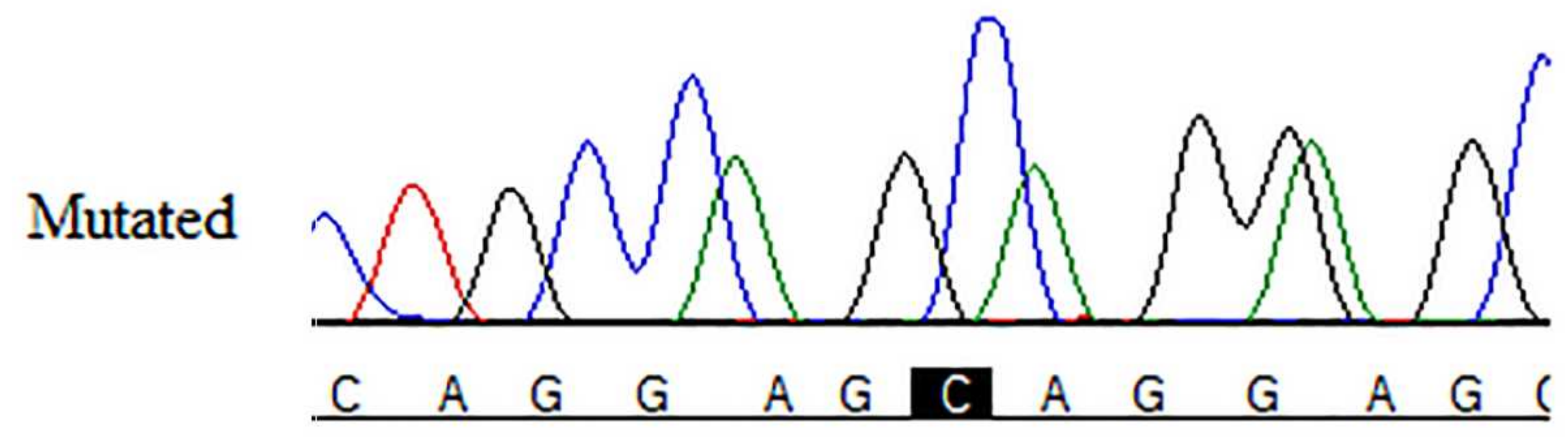

Wild Type

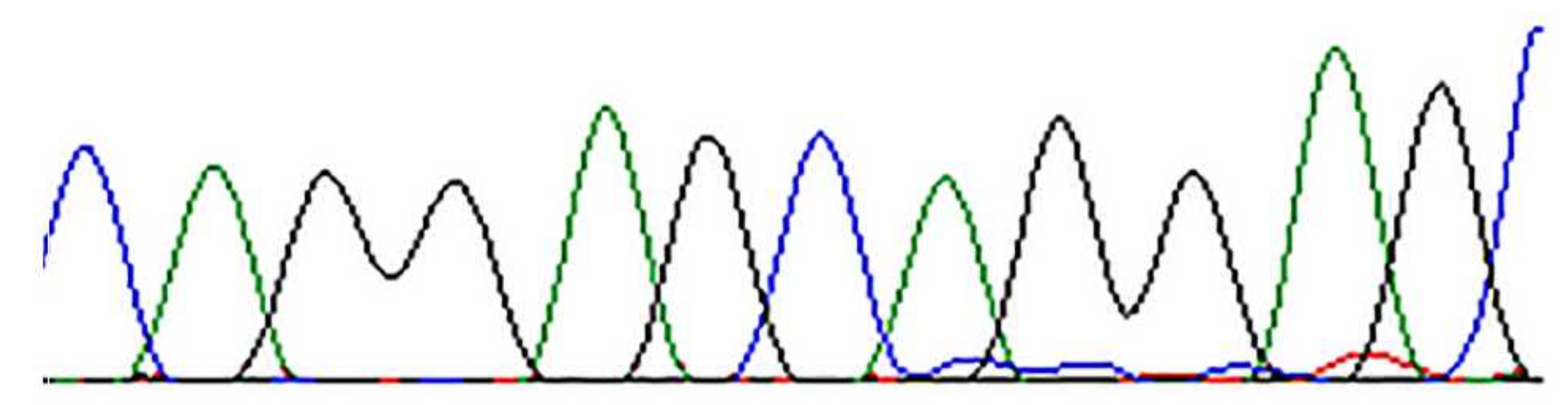




\section{Supplementary material}

\section{TEXT 1: Methods}

3

\section{Subjects}

BVVL or FL diagnosed patients were referred for genetic analysis by the neurologists who are among the authors, mostly by SN who is head of the Neuromuscular Division of Shariati Hospital that is associated with the Tehran University of Medical Sciences. Diagnosis in all cases was confirmed by SN and HS. Family members were recruited when possible. BVVL diagnosis was based on presence of motor neuronopathy with prominent cranial nerve involvement accompanied with hearing impairment. FL diagnosis was based on presence of motor neuronopathy with cranial nerve involvement without hearing impairment. Riboflavin was always prescribed at dosage of $10 \mathrm{mg} / \mathrm{kg}$ body weight/ day. Hearing status was based on self or family reports and pure tone audiometry testing on 27 individuals. All probands and some family members underwent electrodiagnostic (EDX) testing including nerve conduction studies (NCS) and electromyography (EMG) in upper and lower extremities, truncal regions, and cranial regions according to standard procedures (Synergy On Nicolet EDX, Natus, CA, USA). Brain magnetic resonance imaging (MRI), biochemical testings, and/or immunological testings were performed on some patients. The biochemical and immunological testings were performed at least two times. Fluorescent antinuclear antibody (FANA) testing on the serum of two patients was done by standard protocols. Plasma acylcarnitine profiles were obtained by tandem mass spectrometry; plasma samples were obtained from blood taken after at least ten days of not having taken riboflavin medication. MRI was done using a 1.5-T system (MAGNETOM Avanto 1.5 Tesla, Siemens, Germany). T1 and T2-weighted spin echo protocols were used. Muscle and nerve histopathology was performed for one proband by standard protocols. 
Probands and family members were interviewed to obtain information pertaining to BVVL or FL in the families. DNA was isolated from blood cells by standard protocols. Initially, the exons and flanking intronic sequences of $S L C 52 A 3$ in the DNA of the probands were amplified and sequenced as previously described (Dezfouli et al., 2012). Reference sequences used for analysis were NC_000020.10, NM_033409.4, and NP_212134.3. Effects of variant sequences on splicing were assessed with NNSPLICE 0.9 (http://www.fruitfly.org/seq_tools/splice.html) and Human Splicing Finder version 3.1 (HSF 3.1) (http://www.umd.be/HSF/HSF.shtml) softwares. Candidate disease causing variations were screened for segregation with disease status in members of respective families by direct sequencing. Previously unreported mutations were also screened in 300 Iranian control individuals by an allele specific PCR protocol and also sought in the Iranome database (http://iranome.com/) that contains exome data on 800 healthy Iranians. Evolutionary conservation of amino acids affected by the mutations was checked. The exons and flanking intronic sequences of SLC52A2 were screened by the same protocol for patients in whom no or only one SLC52A3 mutated allele had been found. SLC52A2 reference sequences used were NC_000008.10, NM_001253815.2 and NP_001240744.1. Whole exome sequencing was performed for probands in whom SLC52A3 and SLC52A2 mutations had not been found and for three or four unaffected members of each family. The sequencing was done using the SureSelect V6-Post Kit and an Illumina HiSeq 4000 system (Illumina, CA, USA). Sequence alignment was performed against reference genome GRCh37/hg19, and variant callings were done by using ENSEMBL Variant Effect Predictor (http://www.ensembl.org/Tools/VEP) and wANNOVAR (http://wannovar.wglab.org/). Filtering was performed by removing SNPs with a minor allele frequency (MAF) of $>0.01$ in the dbSNP database (http://www.ncbi.nlm.nih.gov/), the Trans-Omics for Precision Medicine program 
50 (https://www.nhlbiwgs.org/), the 1000 Genomes database (www.1000genomes.org), the

51 NHLBI Exome Sequencing Project (http://evs.gs.washington.edu/EVS/), the Exome

52

53

54

55 Aggregation Consortium database (http://exac.broadinstitute.org/), the Genome Aggregation database (http://genomad.broadinstitute.org/), the Greater Middle East Variome Project (http://igm.ucsd.edu/gme/), ENSEMBL (https://www.ensembl.org/index.html), the Healthy Exomes database (https://www.alzforum.org/exomes/hex), the Sequencing Initiative Suomi database (http://www.sisuproject.fi/), the VarCards database (http://varcards.biols.ac.cn/), or the Iranome database (http://iranome.com/), or observed in in-house exome data belonging to approximately 100 unrelated Iranians affected with non-neurological diseases. Among the variations that remained, those that did not affect amino acid change or splicing were removed. Subsequently, a file for each family was prepared that containing retained genes with homozygous or compound heterozygous variations present in the proband and absent in respective unaffected individuals. Though parental consanguinity suggested that causative mutations would most likely be homozygous, compound heterozygous variations were retained for the sake of stringent analysis. Candidate disease causing variations were screened for segregation with disease status by Sanger sequencing in $15-47$ unaffected individuals in the nuclear and extended family of the proband. Segregating mutations were also screened in control individuals as described above.

\section{TEXT 2: Results}

\section{Subjects}

\section{Families with $S L C 52 A 3$ mutations}

BVVL-102 
The proband (BVVL-102-II6) had normal development until the late teens when the patient began to have difficulty in swallowing food. The patient also reports having experienced vertigo. Difficulty in walking and speech problems ensued within one year. Presently, eight years after onset, she has prominent hearing problems and bulbar palsy presentations including dysphagia, dysarthria, and tongue atrophy. The patient is withdrawn and depressed. Although atrophy in her distal limbs is evident, she is independent in walking and performing daily functions.

Reports from the proband on family members and results of genetic analysis (see section on Genetic analysis/ Families with SLC52A3 mutations in Results) prompted clinical examination of other family members. The mother (-I2), now in her mid-50s had hearing problems from when she was in her 20s. She presently presents with difficulties in swallowing and more notably in drinking, difficulties in walking, facial weakness, weakness in the limbs and significant atrophy in the legs. The clinical manifestations of the mother are clearly less severe than those of her daughter (-102-II6) who is almost 30 years younger. Sibling -II3 had leg weakness and hearing defects. Sensorineural hearing defects were confirmed in -102-II3 and -102-II5. EDX results evidenced neuronopathy in the proband and in -I2, -II3 and -II5 (Table S1). All four individuals were diagnosed with BVVL. Unfortunately, transport of -I1, -II1, -II2, and -II4 for critical neurological examination was not possible. Audiometric testing on these individuals revealed that the father (-I1) and siblings -II1 and -II4 had sensorineural hearing loss, and that -II2 was normal.

\section{BVVL-104}

The mother of the proband reports that her child had hearing problems and frequent episodes of upper respiratory tract infections in early childhood, and that the child regularly snored. The child's adenoids and tonsils were sequentially removed before the child was five. 
97 Regardless of these interventions, her snoring evolved into a deep and very loud squealing and she experienced voice change and breathing difficulties. Hand tremor, dysphagia, and walking difficulties ensued. Riboflavin treatment was started at age of nearly ten when BVVL was diagnosed. Although the patient responded favorably, she does not use the drug regularly as prescribed. The mother reports that her daughter's father and paternal grandfather both had some hearing problems. Audiometric testing showed that the mother herself has normal hearing.

\section{BVVL-106 and BVVL-108}

The clinical profiles of the single affected individual of families 106 and 108 are quite similar. Genetic findings prompted assessment of hearing loss in ostensibly unaffected individuals of these families. Audiometric testing was possible for BVVL-108-I2, and her hearing was found to be normal.

\section{BVVL-109 and BVVL-110}

Both probands of BVVL-109 and BVVL-110 had a long disease duration of 27 years. Their clinical features are very similar, although ophthalmoplegia and asymmetry in limb weakness were observed only in BVVL-110-II2. The mother reported that start of hearing loss in BVVL-110-II2 coincided with tonsillitis. Results of genetic analysis suggested that clinical examination of additional members of families 109 and 110 should be performed. In family 109, neurological examinations including EDX were normal for -II2 and -II3, but -II3 had severe sensorineural hearing defects; hearing of -II2 was normal. Family members reported that BVVL-109-II4, who was not examined, also had hearing problems. In family -110, only -I2 and -II6 consented to clinical examination; both were found to be normal. Hearing difficulties were reported for BVVL-110-II1 who was not examined. 
121

122

BVVL-113 is a large two-branched pedigree (Fig. 1A). The proband was definitively diagnosed with BVVL (Table 1). The proband's mother reported that onset of his symptoms coincided with an incidence of severe fever accompanied by upper respiratory tract infection. Pedigree members told us that there are six other individuals (BVVL-113-II1, -II10, -III1, BVVL-113-III10, -III12, and -III13) distributed in the two branches with hearing problems or presentations similar to the proband. Five (all except BVVL-113-III1) were recruited and results of clinical examinations, including EDX evidence of motor neuronopathy, supported BVVL diagnosis in four (all except BVVL-113-II1) (Table S2). BVVL-113-III1, based on presentations described, is also probably affected. The only BVVL associated feature observed in BVVL-113-II1 was hearing loss which was confirmed by auditory testing. This individual who is presently in the early 40s old reported that his hearing problems had started fifteen years earlier immediately after a severe upper respiratory infection. The coincidence of BVVL related symptoms and incidence of upper respiratory infection and fever in -113-II1 and the proband of pedigree BVVL-113 is reminiscent of BVVL onset in the proband of family BVVL-104.

\section{Families without SLC52A3 mutations}

\section{BVVL-103}

BVVL-103-II1 is the only BVVL affected individual in a large highly inbred pedigree. BVVL-103-II1 was apparently normal until the beginning of second decade of life, at which time he presented with facial weakness. His mother also reports onset of tongue atrophy at that same time. Hearing problems were detected within one year. Weakness in hands and feet, and difficulty in walking ensued. Intrinsic hand muscle atrophy and hand tremor are 
now present. His presentations are generally more prominent on the right side. Dysphagia with respect to liquids was more severe than solid food. Brain MRI images were normal. The patient used riboflavin regularly as prescribed for two years from the age of 23 , but seeing no improvement, he stopped using it.

BVVL-111

BVVL-111-II3, who is presently in the mid-30s old, is the only affected individual among four siblings. The patient had hearing problems from when the age of 16 and these significantly worsened with passage of time. He reports that he had no other symptom until three years ago, when he noticed dysarthria, dysphonia and dyspnea after a course of severe and long-lasting respiratory infection. Brain CT scan in lieu of MRI was done because presence of cochlear implant precluded MRI. The scan was unremarkable. Results of thorough clinical laboratory measurements are summarized as follows (Table S3). Red blood cell count and hemoglobin and hematocrit measurements were high; these may reflect the patient's respiratory difficulties. Lactate dehydrogenase (LDH) and creatine phospho-kinase $(\mathrm{CPK})$ measurements were within the normal range. $\mathrm{C}$ reactive protein and erythrocyte sedimentation measurements, serum immunoglobulin and complement levels, and B-cell and T-cell numbers as assessed by flow cytometry measurements of surface markers were normal. However, mildly elevated serum neutrophil and decreased lymphocyte levels and borderline alpha 1 antitrypsin levels were consistent with presence of an inflammatory response (Stockley RA, 2015). This was further supported by presence of anti-nuclear antibody evidenced as the few nuclear dot pattern by immunofluorescent microscopy (Fig. 2A) (Damoiseaux et al., 2019). Results of other autoimmune related measurements were negative. Plasma lupus anticoagulant levels were normal. Amino acid and acylcarnitine 
profiles were completely normal. The patient has been using riboflavin for six months and reports no improvement of symptoms.

FL-101

FL-101-II3 is in the late 30s and the only affected individual among seven siblings. The patient's mother reports that her child experienced an episode of febrile seizure at age of six months, that her gait was abnormal from the time she started to walk at the age of two years, and that ptosis was evident from childhood. The proband herself had no complaints until about the beginning of teenage years when it became difficult for her to endure walking long distances. Atrophy became evident in her legs and was progressive. Presently, she has proximal and distal weakness of upper and lower limbs, more prominent in the right side and associated with axial weakness (neck flexor and neck extensor). Distal weakness of lower limbs evidences as foot drop and steppage gait. There is intrinsic muscle atrophy in her right hand. The patient has facial weakness, but does not manifest bulbar palsy. Electromyography study of cranial region showed chronic neurogenic MUP (motor unit potential) pattern in mentalis and trapezius muscles, but normal MUP pattern in tongue and masseter muscles. She does not have hearing problems. She was independent until the age of 31 yrs., but now needs help for some tasks including climbing stairs. The patient was diagnosed with FL at in her early 30s. Brain MRI images were normal. Results of thorough clinical laboratory measurements are summarized as follows (Table S4). There were multiple indications consistent with possible immune anomalies. The cytotoxic T-cell level was slightly high as compared to normal range, and the helper to cytotoxic $\mathrm{T}$ cell ratio was inverted. The $\mathrm{B}$ cell level as assessed by CD19 measurement was at the lower end of the normal range. Polyclonal immunoglobulin $\mathrm{G}$ and $\mathrm{M}$ levels in the serum were elevated. This increase, and elevated serum neutrophil and alpha 1 antitrypsin levels and decreased lymphocyte levels were 
consistent with presence of an inflammatory response (Stockley RA, 2015). Measurements of

191

192

193

194

195

196

197

198 various autoimmune factors, including anti-dsDNA antibodies and lupus anticoagulants, were within normal ranges. However, presence of anti-nuclear antibodies that evidenced with the fine speckled pattern in the nucleus by fluorescent microscopy, is suggestive of an autoimmune and/or inflammatory response (Fig. 2B) (Damoiseaux et al., 2019). Mildly elevated LDH and CK levels are consistent with muscle involvement, and elevated lactate and lactate to pyruvate ratio are consistent with mitochondrial dysfunction. Some parameters of the patient's acylcarnitine profile, including methylmalonycarnitine (C4DC), hydroxyisovalerylcarnitine $(\mathrm{C} 5 \mathrm{OH}), \quad$ decenolylcarnitine $(\mathrm{C} 10: 1), \quad$ and tetradecadienolycarnitine (C14:1) were not within the normal range. Abnormal acylcarnitine profiles may reflect defects in mitochondrial fatty acid beta-oxidation catabolism (Wanders et al., 2010).

Results of muscle histology confirmed presence of neurogenic muscle atrophy and some mitochondrial dysfunction that was evidenced in the laboratory results and clinical examinations. The muscle biopsy from the left vastus lateralis revealed marked muscle atrophy with a fascicular atrophy pattern. The remaining fibers were round and multiple nuclear clumps were associated with hypertrophied fibers with occasional fiber splitting (Fig 3A). Endomysial connective tissue was increased with prominent adipose tissue replacement. There was no evidence of inflammatory cell infiltration. Staining for ATPase showed uniformity of type 2 fibers. Ragged red fibers were not seen in modified Gomori Trichrome staining, but succinate dehydrogenase (SDH) staining showed abnormal peripheral mitochondrial proliferation in some fibers (Fig. 3B). The SDH plus cytochrome oxidase $(\mathrm{COX})$ reactions revealed a notable number of fibers with reduced COX activity which is consistent with neurogenic atrophy with some mitochondrial dysfunction (Fig. 3C). 
Histology of a biopsy from the left sural nerve showed no evidence of vasculitis, neither granuloma nor amyloid deposition (Fig. 3D).

The proband has regularly used riboflavin for seven years, but reports no improvement and instead progression of disease presentations.

\section{TEXT 3: Discussion}

Single mutated SLC52A3 alleles in BVVL/FL diagnosed patients previously or now reported include c.37G>A(p.Gly13Arg), c.58A >C(p.Ile20Leu), c.62A $>\mathrm{G}(\mathrm{p}$. Asn21Ser $)$,

c.106G>A(p.Glu36Lys),

c.113G $>$ C(p.Trp38Ser), c. $374 \mathrm{C}>\mathrm{A}(\mathrm{p}$. Thr125Asn $)$,

c.1124G>A(p.Gly375Asp), c.1296C>A(p.Cys432X), and c.1371C>G(p.Phe457Leu).

\section{References referred to above:}

Dezfouli MA, Yadegari S, Nafissi S, et al. Four novel C20orf54 mutations identified in Brown-Vialetto Van Laere syndrome patients. J Hum Genet 2012;57(9):613-7.

Stockley RA. The multiple facets of alpha-1-antitrypsin. Ann Transl Med 2015;3(10):130.

Damoiseaux J, Andrade LEC, Carballo OG, et al. Clinical relevance of HEp-2 indirect immunofluorescent patterns: the International Consensus on ANA patterns (ICAP) perspective. Ann Rheum Dis 2019;78(7):879-89.

Wanders RJ, Ruiter JP, L IJ, et al. The enzymology of mitochondrial fatty acid beta-oxidation and its application to follow-up analysis of positive neonatal screening results. J Inherit Metab Dis 2010;33(5):479-94.

\section{TEXT 4: Additional references pertaining to main text of article}

- Velleman SG, Sporer KR, Ernst CW, et al. Versican, matrix Gla protein, and death-associated protein expression affect muscle satellite cell proliferation and differentiation. Poult Sci 2012;91(8):1964-73. 
- McRae N, Forgan L, McNeill B, et al. Glucocorticoids Improve Myogenic Differentiation In Vitro by Suppressing the Synthesis of Versican, a Transitional Matrix Protein Overexpressed in Dystrophic Skeletal Muscles. Int J Mol Sci 2017;18(12).

- McCulloch DR, Nelson CM, Dixon LJ, et al. ADAMTS metalloproteases generate active versican fragments that regulate interdigital web regression. Dev Cell 2009;17(5):687-98.

- Hope C, Foulcer S, Jagodinsky J, et al. Immunoregulatory roles of versican proteolysis in the myeloma microenvironment. Blood 2016;128(5):680-5.

References pertaining to BAIAP2:

- Ahmed S, Goh WI, Bu W. I-BAR domains, IRSp53 and filopodium formation. Semin Cell Dev Biol 2010;21(4):350-6.

- Scita G, Confalonieri S, Lappalainen P, et al. IRSp53: crossing the road of membrane and actin dynamics in the formation of membrane protrusions. Trends Cell Biol 2008;18(2):52-60.

- Suetsugu S, Toyooka K, Senju Y. Subcellular membrane curvature mediated by the BAR domain superfamily proteins. Semin Cell Dev Biol 2010;21(4):340-9.

- Abbott MA, Wells DG, Fallon JR. The insulin receptor tyrosine kinase substrate p58/53 and the insulin receptor are components of CNS synapses. J Neurosci 1999;19(17):7300-8.

- Bockmann J, Kreutz MR, Gundelfinger ED, et al. ProSAP/Shank postsynaptic density proteins interact with insulin receptor tyrosine kinase substrate IRSp53. J Neurochem 2002;83(4):1013-7.

- Kim MH, Choi J, Yang J, et al. Enhanced NMDA receptor-mediated synaptic transmission, enhanced long-term potentiation, and impaired learning and memory in mice lacking IRSp53. J Neurosci 2009;29(5):1586-95.

- Sawallisch C, Berhorster K, Disanza A, et al. The insulin receptor substrate of 53 kDa (IRSp53) limits hippocampal synaptic plasticity. J Biol Chem 2009;284(14):9225-36.

- Han JW, Zheng HF, Cui Y, et al. Genome-wide association study in a Chinese Han population identifies nine new susceptibility loci for systemic lupus erythematosus. Nat Genet 2009;41(11):1234-7.

- Wang C, Ahlford A, Jarvinen TM, et al. Genes identified in Asian SLE GWASs are also associated with SLE in Caucasian populations. Eur J Hum Genet 2013;21(9):994-9.

- Lessard CJ, Sajuthi S, Zhao J, et al. Identification of a Systemic Lupus Erythematosus Risk Locus Spanning ATG16L2, FCHSD2, and P2RY2 in Koreans. Arthritis Rheumatol 2016;68(5):1197209.

- Zhang Y, Bo L, Zhang H, et al. E26 transformation-specific-1 (ETS1) and WDFY family member 4 (WDFY4) polymorphisms in Chinese patients with rheumatoid arthritis. Int J Mol Sci 2014;15(2):2712-21.

- Mclntosh LA, Marion MC, Sudman M, et al. Genome-Wide Association Meta-Analysis Reveals Novel Juvenile Idiopathic Arthritis Susceptibility Loci. Arthritis Rheumatol 2017;69(11):2222-32.

- Kochi Y, Kamatani Y, Kondo Y, et al. Splicing variant of WDFY4 augments MDA5 signalling and the risk of clinically amyopathic dermatomyositis. Ann Rheum Dis 2018;77(4):602-11.

- Filimonenko M, Isakson P, Finley KD, et al. The selective macroautophagic degradation of aggregated proteins requires the PI3P-binding protein Alfy. Mol Cell 2010;38(2):265-79.

- Kadir R, Harel T, Markus B, et al. ALFY-Controlled DVL3 Autophagy Regulates Wnt Signaling, Determining Human Brain Size. PLoS Genet 2016;12(3):e1005919.

- Yuan Q, Li Y, Li J, et al. WDFY4 Is Involved in Symptoms of Systemic Lupus Erythematosus by Modulating B Cell Fate via Noncanonical Autophagy. J Immunol 2018;201(9):2570-78.

References pertaining to TNFSF13B and BAFF: 
- De Paepe B, Creus KK, De Bleecker JL. The tumor necrosis factor superfamily of cytokines in the inflammatory myopathies: potential targets for therapy. Clin Dev Immunol 2012;2012:369432.

- Locksley RM, Killeen N, Lenardo MJ. The TNF and TNF receptor superfamilies: integrating mammalian biology. Cell 2001;104(4):487-501.

- Karpusas M, Cachero TG, Qian F, et al. Crystal structure of extracellular human BAFF, a TNF family member that stimulates B lymphocytes. J Mol Biol 2002;315(5):1145-54.

- Gavin AL, Ait-Azzouzene D, Ware CF, et al. DeltaBAFF, an alternate splice isoform that regulates receptor binding and biopresentation of the B cell survival cytokine, BAFF. J Biol Chem 2003;278(40):38220-8.

- Schneider P, Mackay F, Steiner V, et al. BAFF, a novel ligand of the tumor necrosis factor family, stimulates B cell growth. J Exp Med 1999;189(11):1747-56.

- Moore PA, Belvedere O, Orr A, et al. BLyS: member of the tumor necrosis factor family and B lymphocyte stimulator. Science 1999;285(5425):260-3.

- Mueller CG, Boix C, Kwan WH, et al. Critical role of monocytes to support normal B cell and diffuse large B cell lymphoma survival and proliferation. J Leukoc Biol 2007;82(3):567-75.

- Huard B, Schneider P, Mauri D, et al. T cell costimulation by the TNF ligand BAFF. J Immunol 2001;167(11):6225-31.

- Sutherland AP, Ng LG, Fletcher CA, et al. BAFF augments certain Th1-associated inflammatory responses. J Immunol 2005;174(9):5537-44.

- Hu S, Wang R, Zhang M, et al. BAFF promotes T cell activation through the BAFF-BAFF-R-PI3K-Akt signaling pathway. Biomed Pharmacother 2019;114:108796.

- Pers JO, Daridon C, Devauchelle V, et al. BAFF overexpression is associated with autoantibody production in autoimmune diseases. Ann N Y Acad Sci 2005;1050:34-9.

- Stohl W, Metyas S, Tan SM, et al. B lymphocyte stimulator overexpression in patients with systemic lupus erythematosus: longitudinal observations. Arthritis Rheum 2003;48(12):3475-86.

- Seyler TM, Park YW, Takemura S, et al. BLyS and APRIL in rheumatoid arthritis. J Clin Invest 2005;115(11):3083-92.

- Szodoray P, Jonsson R. The BAFF/APRIL system in systemic autoimmune diseases with a special emphasis on Sjogren's syndrome. Scand J Immunol 2005;62(5):421-8.

- Thangarajh M, Gomes A, Masterman T, et al. Expression of B-cell-activating factor of the TNF family (BAFF) and its receptors in multiple sclerosis. J Neuroimmunol 2004;152(1-2):183-90.

- Zhu XJ, Shi Y, Zhang F, et al. Reduced tumour necrosis factor receptor superfamily $13 \mathrm{C}$ inversely correlated with tumour necrosis factor superfamily $13 \mathrm{~B}$ in patients with immune thrombocytopenia. Br J Haematol 2014;166(5):783-91.

- Mackay F, Woodcock SA, Lawton P, et al. Mice transgenic for BAFF develop lymphocytic disorders along with autoimmune manifestations. J Exp Med 1999;190(11):1697-710.

- Schiemann B, Gommerman JL, Vora K, et al. An essential role for BAFF in the normal development of B cells through a BCMA-independent pathway. Science 2001;293(5537):2111-4.

- Gross JA, Dillon SR, Mudri S, et al. TACI-Ig neutralizes molecules critical for B cell development and autoimmune disease. impaired B cell maturation in mice lacking BLyS. Immunity 2001;15(2):289-302.

- Steri M, Orru V, Idda ML, et al. Overexpression of the Cytokine BAFF and Autoimmunity Risk. N Engl J Med 2017;376(17):1615-26. 
346

347 
